\title{
The imprint of surface fluxes and transport on variations in total column carbon dioxide
}

\author{
G. Keppel-Aleks ${ }^{1}$, P. O. Wennberg ${ }^{1}$, R. A. Washenfelder ${ }^{2}$, D. Wunch ${ }^{1}$, T. Schneider ${ }^{1}$, G. C. Toon ${ }^{4}$, R. J. Andres ${ }^{3}$, \\ J.-F. Blavier ${ }^{4}$, B. Connor ${ }^{5}$, K. J. Davis ${ }^{6}$, A. R. Desai ${ }^{7}$, J. Messerschmidt ${ }^{8}$, J. Notholt ${ }^{8}$, C. M. Roehl ${ }^{1}$, V. Sherlock ${ }^{9}$, \\ B. B. Stephens ${ }^{10}$, S. A. Vay ${ }^{11}$, and S. C. Wofsy ${ }^{12}$ \\ ${ }^{1}$ California Institute of Technology, Pasadena, CA, USA \\ ${ }^{2}$ National Oceanic and Atmospheric Administration, Boulder, CO, USA \\ ${ }^{3}$ Oak Ridge National Laboratory, Oak Ridge, TN, USA \\ ${ }^{4}$ NASA Jet Propulsion Laboratory, Pasadena, CA, USA \\ ${ }^{5}$ BC Consulting, New Zealand \\ ${ }^{6}$ The Pennsylvania State University, University Park, PA, USA \\ ${ }^{7}$ University of Wisconsin, Madison, WI, USA \\ ${ }^{8}$ University of Bremen, Bremen, Germany \\ ${ }^{9}$ National Institute of Water and Atmospheric Research, Wellington, New Zealand \\ ${ }^{10}$ National Center for Atmospheric Research, Boulder, CO, USA \\ ${ }^{11}$ NASA Langley Research Center, Langley, VA, USA \\ ${ }^{12}$ Harvard University, Cambridge, MA, USA
}

Correspondence to: G. Keppel-Aleks (gka@alum.mit.edu)

Received: 30 June 2011 - Published in Biogeosciences Discuss.: 27 July 2011

Revised: 2 January 2012 - Accepted: 9 February 2012 - Published: 1 March 2012

\begin{abstract}
New observations of the vertically integrated $\mathrm{CO}_{2}$ mixing ratio, $\left\langle\mathrm{CO}_{2}\right\rangle$, from ground-based remote sensing show that variations in $\left\langle\mathrm{CO}_{2}\right\rangle$ are primarily determined by large-scale flux patterns. They therefore provide fundamentally different information than observations made within the boundary layer, which reflect the combined influence of large-scale and local fluxes. Observations of both $\left\langle\mathrm{CO}_{2}\right\rangle$ and $\mathrm{CO}_{2}$ concentrations in the free troposphere show that large-scale spatial gradients induce synoptic-scale temporal variations in $\left\langle\mathrm{CO}_{2}\right\rangle$ in the Northern Hemisphere midlatitudes through horizontal advection. Rather than obscure the signature of surface fluxes on atmospheric $\mathrm{CO}_{2}$, these synopticscale variations provide useful information that can be used to reveal the meridional flux distribution. We estimate the meridional gradient in $\left\langle\mathrm{CO}_{2}\right\rangle$ from covariations in $\left\langle\mathrm{CO}_{2}\right\rangle$ and potential temperature, $\theta$, a dynamical tracer, on synoptic timescales to evaluate surface flux estimates commonly used in carbon cycle models. We find that simulations using Carnegie Ames Stanford Approach (CASA) biospheric fluxes underestimate both the $\left\langle\mathrm{CO}_{2}\right\rangle$ seasonal cycle amplitude throughout the Northern Hemisphere midlatitudes and
\end{abstract}

the meridional gradient during the growing season. Simulations using CASA net ecosystem exchange (NEE) with increased and phase-shifted boreal fluxes better fit the observations. Our simulations suggest that climatological mean CASA fluxes underestimate boreal growing season NEE (between $45-65^{\circ} \mathrm{N}$ ) by $\sim 40 \%$. We describe the implications for this large seasonal exchange on inference of the net Northern Hemisphere terrestrial carbon sink.

\section{Introduction}

Accurate determination of surface fluxes of carbon dioxide is important both to predict future climate and increasingly to support climate and energy policy. The long-term trend in atmospheric $\mathrm{CO}_{2}$ depends not only on anthropogenic emissions; natural fluxes of $\mathrm{CO}_{2}$ to the ocean and terrestrial biosphere control the fraction of anthropogenic $\mathrm{CO}_{2}$, presently $\sim 45 \%$, that remains in the atmosphere (Gloor et al., 2010). These natural fluxes respond to changes in atmospheric composition and climate on interannual and longer timescales. 
Partitioning uptake and release of $\mathrm{CO}_{2}$ among its terrestrial and oceanic components is necessary to gain insight into the processes controlling these fluxes.

Ideally, self-consistent flux estimates over spatial scales ranging from local to global could be determined from a single set of observations. In reality, no single type of measurement is capable of providing such a constraint. For example, observations of atmospheric $\mathrm{O}_{2}$ mixing ratio (Keeling et al., 1996) provide an estimate of net ocean and biospheric uptake globally, but provide little or no information about the spatial distribution of fluxes. At local scales, terrestrial biospheric carbon fluxes can be measured quite accurately via inventory (e.g., changes in carbon stocks, Saatchi et al., 2007) and by atmospheric observations (e.g., eddy-covariance measurements, Baldocchi, 2008). Such measurements are, however, representative only of small spatial scales $\left(<10 \mathrm{~km}^{2}\right)$; other data sets such as measures of land color or chlorophyll fluorescence from satellites are needed to scale the local flux estimates to regional and global scales (e.g., Beer et al., 2010; Frankenberg et al., 2011). Likewise, estimation of ocean fluxes from surface $p \mathrm{CO}_{2}$ measurements requires substantial upscaling of sparse observations.

To infer surface fluxes at intermediate spatial scales (e.g., continental scales), inverse modeling of atmospheric carbon dioxide observations has been used in a variety of approaches. For example, the TransCom experiment estimated continental fluxes at scales of $10^{7} \mathrm{~km}^{2}$ using a suite of transport models, each constrained by measurements of boundary layer $\mathrm{CO}_{2}$ mixing ratio, $\left[\mathrm{CO}_{2}\right]$ (Gurney et al., 2002). CarbonTracker optimizes regional fluxes via $\mathrm{CO}_{2}$ data assimilation (Peters et al., 2007). Like other methods, inverse modeling has its limitations. Although the global network to monitor $\mathrm{CO}_{2}$ is growing, there are only limited observations of atmospheric $\mathrm{CO}_{2}$, most of which are obtained within the planetary boundary layer. The relative contribution of local versus large-scale fluxes to variations in $\mathrm{CO}_{2}$ varies based on location, time of day, and season, complicating the use of boundary layer $\mathrm{CO}_{2}$ observations to constrain fluxes over a range of spatial scales.

Inverse modeling is also complicated by a more fundamental limitation. The ability to use surface concentration data to infer fluxes requires accurate modeling of boundary layer height and rates of entrainment between the boundary layer and the free troposphere. Gradients in atmospheric carbon dioxide are influenced by the covariance between the strength of surface fluxes and the strength of vertical mixing (Denning et al., 1995). Primarily as a result of this covariance, studies have shown that inversion results are very sensitive to how vertical mixing is represented in transport models (Stephens et al., 2007).

Total column carbon dioxide, denoted in this paper as $\left\langle\mathrm{CO}_{2}\right\rangle$ but denoted as $X_{\mathrm{CO}_{2}}$ elsewhere, is a new measurement that will complement surface data in inverse studies by bridging the spatial gap between the small-scale flux constraints provided by direct flux observations or boundary layer con- centration data and the global constraints provided by atmospheric $\mathrm{O}_{2}$. Because the column integrates not only boundary layer $\mathrm{CO}_{2}$ but also free tropospheric $\mathrm{CO}_{2}$, its footprint is much larger. A companion paper (Keppel-Aleks et al., 2011), hereafter KWS11, shows that simulated $\left\langle\mathrm{CO}_{2}\right\rangle$ has a large footprint and is largely insensitive to assumptions about small-scale mixing. In the KWS11 simulations, variations in $\left\langle\mathrm{CO}_{2}\right\rangle$ at all timescales are primarily tied to large-scale rather than local fluxes. Diurnal changes in the column are only weakly influenced by local fluxes, while synoptic-scale variations in the column are due primarily to advection across the mean hemispheric-scale north-south gradient.

Here, we use data from the Total Carbon Column Observing Network (TCCON) to test the simulations of KWS11. TCCON is a network of high resolution ground-based Fourier transform spectrometers (FTS) that obtain direct solar absorption spectra (Wunch et al., 2011). We focus our analysis on two diagnostics for variations in the column, described in Sect. 2.1. The first is the seasonal cycle amplitude (SCA), which quantifies the seasonal variation in $\left\langle\mathrm{CO}_{2}\right\rangle$ at a given location. The second is the north-south gradient in $\left\langle\mathrm{CO}_{2}\right\rangle$, which can be estimated even from sparse ground-based observations using covariations in observed $\left\langle\mathrm{CO}_{2}\right\rangle$ and a dynamical tracer such as potential temperature, $\theta$ (KWS11).

In this paper, we evaluate the information content in $\left\langle\mathrm{CO}_{2}\right\rangle$ observations. Specifically, we compare diurnal variations in TCCON $\left\langle\mathrm{CO}_{2}\right\rangle$ data with eddy covariance flux data to determine the contribution of local surface fluxes to variations in $\left\langle\mathrm{CO}_{2}\right\rangle$. We compare temporal variations in $\left\langle\mathrm{CO}_{2}\right\rangle$ at synoptic timescales with spatial gradients in free tropospheric $\mathrm{CO}_{2}$ data from aircraft to understand the imprint of horizontal advection on $\left\langle\mathrm{CO}_{2}\right\rangle$. A comparison of variations in $\left\langle\mathrm{CO}_{2}\right\rangle$ to variations in local fluxes (eddy covariance observations) and gradients in the free troposphere (aircraft observations) both confirm that $\left\langle\mathrm{CO}_{2}\right\rangle$ variations primarily reflect large-scale flux information. We illustrate how $\left\langle\mathrm{CO}_{2}\right\rangle$ observations can be used to constrain global carbon fluxes and address how they can be used in future studies to complement more established observations.

\section{Data and methods}

\subsection{Ground based total column data}

We use $\left\langle\mathrm{CO}_{2}\right\rangle$ data from TCCON observatories. The first dedicated TCCON observatories became operational in 2004 , and the network has subsequently grown. Table 1 lists the sites used in this study, limited to midlatitude sites that have obtained data over at least one complete annual cycle. We summarize the data acquisition and retrieval method; more details are provided in Wunch et al. (2011) and references therein. 
Table 1. TCCON sites and their median seasonal cycle amplitudes (SCA) in ppm.

\begin{tabular}{lllrrrrr}
\hline Site & Lat & Lon & $\begin{array}{r}\text { Observed } \\
\text { SCA }\end{array}$ & $\begin{array}{r}\text { CASA } \\
\text { SCA }\end{array}$ & $\begin{array}{r}\text { Boreal } \\
\text { amplified } \\
\text { SCA }\end{array}$ & $\begin{array}{r}\text { Early } \\
\text { growing } \\
\text { season SCA }\end{array}$ & $\begin{array}{r}\text { CarbonTracker } \\
\text { SCA }\end{array}$ \\
\hline Bialystok & $52^{\circ} \mathrm{N}$ & $20^{\circ} \mathrm{E}$ & 9.1 & $6.7 \pm 0.3$ & $8.4 \pm 0.3$ & $9.8 \pm 0.2$ & $8.2 \pm 0.3$ \\
Park Falls & $46^{\circ} \mathrm{N}$ & $90^{\circ} \mathrm{W}$ & $8.6 \pm 1.0$ & $6.9 \pm 0.5$ & $8.8 \pm 0.4$ & $9.6 \pm 0.4$ & $8.2 \pm 1.0$ \\
Lamont & $37^{\circ} \mathrm{N}$ & $100^{\circ} \mathrm{W}$ & $6.8 \pm 1.0$ & $5.3 \pm 0.2$ & $6.6 \pm 0.3$ & $7.3 \pm 0.4$ & $5.8 \pm 0.6$ \\
Pasadena & $34^{\circ} \mathrm{N}$ & $119^{\circ} \mathrm{W}$ & 5.9 & $4.4 \pm 0.2$ & $5.3 \pm 0.3$ & $5.9 \pm 0.2$ & $4.9 \pm 0.2$ \\
Lauder & $45^{\circ} \mathrm{S}$ & $170^{\circ} \mathrm{E}$ & $1.7 \pm 0.3$ & $0.9 \pm 0.2$ & $1.1 \pm 0.2$ & $1.2 \pm 0.3$ & $1.1 \pm 0.2$ \\
\hline
\end{tabular}

Briefly, TCCON observatories use FTS to record high resolution spectra $\left(0.02 \mathrm{~cm}^{-1}\right)$ in the near infrared (3800$15500 \mathrm{~cm}^{-1}$ ). A profile scaling retrieval is used to determine the vertical $\mathrm{CO}_{2}$ column from observed spectra. A priori $\mathrm{CO}_{2}$ profiles are generated using an analytical function that varies seasonally and meridionally based on GLOBALVIEW $\mathrm{CO}_{2}$ in the troposphere and applies the age-of-air measurements of Andrews et al. (2001) in the stratosphere. Temperature, water vapor profiles, and tropopause pressure from NCEP reanalysis (Kalnay et al., 1996) are used to map the assumed profile onto 71 vertical layers at $1 \mathrm{~km}$ resolution. Gases, including $\mathrm{CO}_{2}, \mathrm{O}_{2}$, and $\mathrm{H}_{2} \mathrm{O}$ are retrieved simultaneously in selected spectral windows. The $\mathrm{CO}_{2}$ retrieval scales the a priori profile to best match the recorded spectrum in two spectral windows centered at $6220 \mathrm{~cm}^{-1}\left(80 \mathrm{~cm}^{-1}\right.$ wide) and $6339 \mathrm{~cm}^{-1}\left(85 \mathrm{~cm}^{-1}\right.$ wide). The retrieved column abundance $\left[\mathrm{mol} \mathrm{m}^{-2}\right]$ is normalized by the retrieved column abundance of $\mathrm{O}_{2}$ to yield $\left\langle\mathrm{CO}_{2}\right\rangle$ [ppm].

TCCON data have been rigorously calibrated against aircraft profiles of $\mathrm{CO}_{2}$ and are traceable to World Meteorological Organization standards (Wunch et al., 2010). After calibration, the accuracy and precision are both better than $0.2 \%$ $\left(0.8 \mathrm{ppm}\right.$ in $\left.\left\langle\mathrm{CO}_{2}\right\rangle\right)$. In the analysis presented here, we have used simultaneous measurements of $\langle\mathrm{CO}\rangle$ to remove the local fossil component of observed $\mathrm{CO}_{2}$ for data obtained at the Pasadena site, in the Los Angeles urban area (Wunch et al., 2009). Such a localized source will not be captured by the simulations described in this paper, which were run at moderate resolution $\left(2^{\circ}\right.$ by $\left.2.5^{\circ}\right)$. More details are provided in Appendix A. At the other sites, $\left\langle\mathrm{CO}_{2}\right\rangle$ and $\langle\mathrm{CO}\rangle$ are not well correlated, so no empirical correction was applied.

Figure 1 shows the daily median $\left\langle\mathrm{CO}_{2}\right\rangle$ at the sites used in this study. We include all observations for which the retrieval uncertainty is $<1.5 \mathrm{ppm}$. These timeseries show variability at several timescales: a long-term secular increase, seasonal variations, particularly in the Northern Hemisphere, and day-to-day variations. There is also substantial interannual variability in the SCA, which is discussed in Sect. 3.4.

Because the column data are sparse and not all the observatories have operated simultaneously, we focus on a statistical comparison of the data with simulations. For each site, we subtract the linear trend in $\left\langle\mathrm{CO}_{2}\right\rangle$ at Lauder, New

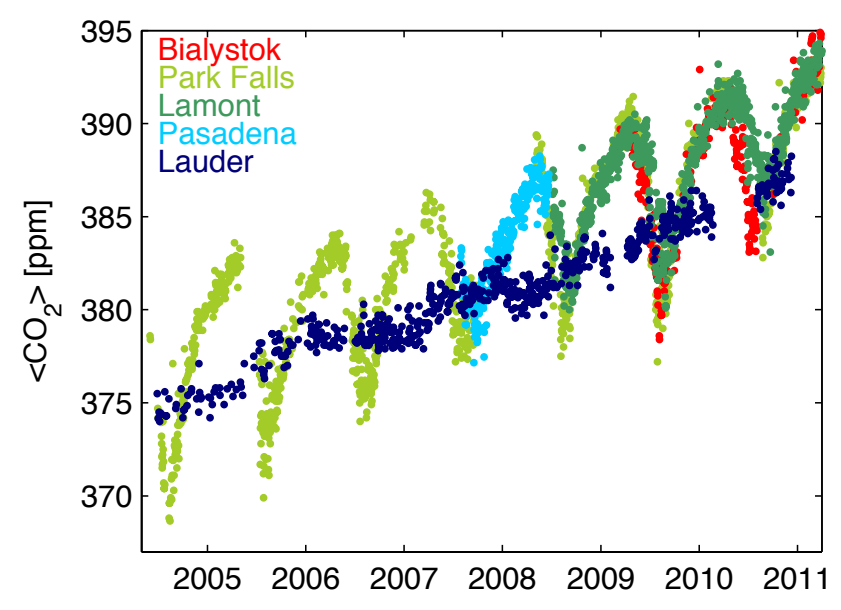

Fig. 1. Daily median $\left\langle\mathrm{CO}_{2}\right\rangle$ at five TCCON sites. Details about the location and operational dates for each site are provided in Table 1.

Zealand, a Southern Hemisphere site with small seasonal and interannual variability (Fig. 1). Thus, the detrended data retain the absolute $\left\langle\mathrm{CO}_{2}\right\rangle$ offset among sites. We then compare the seasonal variation in $\left\langle\mathrm{CO}_{2}\right\rangle$ by computing the peak-totrough seasonal cycle amplitude as the difference between maximum monthly median $\left\langle\mathrm{CO}_{2}\right\rangle$ and the minimum monthly median $\left\langle\mathrm{CO}_{2}\right\rangle$ in the preceding growing season.

We estimate the north-south gradient across TCCON sites using the covariation between $\left\langle\mathrm{CO}_{2}\right\rangle$ and $\theta$ at $700 \mathrm{hPa}$, a dynamical tracer, as described in KWS11 Sect. 3.2. Here we provide a brief rationale for this method, refering readers to KWS11 for a more complete description. The vertically integrated $\left\langle\mathrm{CO}_{2}\right\rangle$ and $\theta$ at $700 \mathrm{hPa}$ observed at TCCON stations covary on synoptic timescales because large-scale eddy activity in the atmosphere advects both tracer fields. We can use $\theta$ to estimate the meridional distance by which an airmass was displaced, because $\theta$ is conserved following adiabatic motion, and then infer the north-south gradient in $\left\langle\mathrm{CO}_{2}\right\rangle$ from the estimated meridional displacement and temporal fluctuations in $\left\langle\mathrm{CO}_{2}\right\rangle$. Although diabatic effects will modify $\theta$ and local fluxes will affect variations in $\left\langle\mathrm{CO}_{2}\right\rangle$, it is possible to infer the large-scale meridional gradient in $\left\langle\mathrm{CO}_{2}\right\rangle$ given adequate data using this method (KWS11). 
The daily mean $\left\langle\mathrm{CO}_{2}\right\rangle$ timeseries from TCCON sites are gap-filled using a cubic spline before we apply a 3 to 21 day bandpass filter to isolate synoptic-scale variations in $\left\langle\mathrm{CO}_{2}\right\rangle$. This removes seasonal variations at frequencies lower than 21 days and mesocale variations at frequency higher than three days and so, among the dynamically generated $\left\langle\mathrm{CO}_{2}\right\rangle$ variations, isolates those generated by large-scale eddies. Our results are not sensitive to the exact filter cutoffs; using a 3-14 day filter changes the results by only $1-2 \%$, as does changing the high frequency cutoff by one day. We denote the bandpass-filtered variations as $\left\langle\mathrm{CO}_{2}\right\rangle^{\prime}$. We use NCEP reanalysis data to calculate bandpass filtered variations and the meridional $\theta$ gradient at each site to estimate the meridional displacement, $L$, of observed air parcels from a reference latitude with monthly mean potential temperature $\bar{\theta}_{0}$ :

$L=\frac{\theta^{\prime}-\bar{\theta}_{0}}{\partial_{y} \bar{\theta}}$.

We then use the meridional displacement and variations in $\left\langle\mathrm{CO}_{2}\right\rangle$ to calculate the meridional gradient, $\partial \widehat{y} \widehat{\left\langle\mathrm{CO}_{2}\right\rangle}$ $\left[\mathrm{ppb} \mathrm{km}{ }^{-1}\right]$ :

$\partial_{y} \widehat{\left\langle\mathrm{CO}_{2}\right\rangle}=\frac{\left\langle\mathrm{CO}_{2}\right\rangle^{\prime}}{L} \times 1000$.

Here, we use the overhat to indicate that the gradient is an estimated, rather than directly observed, quantity.

We calculate $\partial \widehat{y\left\langle\mathrm{CO}_{2}\right\rangle}$ only where there is more than two years of data from a single site. Additionally, direct calculation of $\partial_{y} \widehat{\left\langle\mathrm{CO}_{2}\right\rangle}$ using this method only works well in the midlatitudes where eddy activity is substantial and significant $\mathrm{CO}_{2}$ and $\theta$ gradients exist (KWS11). We can, however, use $\theta$ to estimate meridional displacements everywhere outside the tropics. Because the mean westerly wind in the midlatitudes is $8.5 \mathrm{~m} \mathrm{~s}^{-1}$ during the summer, during one day, the column is influenced by airmasses originating more than $700 \mathrm{~km}$ upwind. Because the zonal winds are so strong, it is difficult not to alias transport error when comparing observations to a model. The use of a dynamically informed, rather than simply a geographic coordinate, facilitates intercomparison between data and models (KWS11). Therefore, we compare $\left\langle\mathrm{CO}_{2}\right\rangle$ at various TCCON sites as a function of the estimated meridional displacement. However, we only calculate $\partial \widehat{\left.\partial_{y} \widehat{C O}_{2}\right\rangle}$ directly from the observations at Park Falls and Lamont because of these methodological and data constraints.

\subsection{Net ecosystem exchange estimated from column drawdown}

We examine diurnal variations in $\left\langle\mathrm{CO}_{2}\right\rangle$ by computing the mass change in the total column over the course of a single day. Because we only obtain measurements during daylight, we define diurnal variations as the daytime drawdown in $\left\langle\mathrm{CO}_{2}\right\rangle$. The vertical column of any gas, $\mathrm{VC}_{\mathrm{G}}\left[\mathrm{mol} \mathrm{m}^{-2}\right]$, is the product of the dry air, vertically averaged mixing ratio of the gas, $\langle\mathrm{G}\rangle$, and the mass of the atmospheric column as expressed in Eq. (3):

$\mathrm{VC}_{\mathrm{G}}=\langle G\rangle \cdot \mathrm{VC}_{\mathrm{air}} \approx\langle G\rangle \cdot \frac{P_{\mathrm{s}}-P_{q}}{g \cdot M_{\mathrm{air}}}$

where $\mathrm{VC}_{\text {air }}$ is the vertical column of dry air, $P_{\mathrm{s}}$ is the surface pressure, $P_{q}$ is the vertically integrated contribution of water to the surface pressure, $g$ the gravitational acceleration, and $M_{\text {air }}$ the molecular mass of air.

We differentiate Eq. (3), assuming the vertical column mass of air is constant, to determine the time rate of change in $\mathrm{VC}_{\mathrm{CO}_{2}}$ attributable to changes in the vertically averaged mixing ratio, $\left\langle\mathrm{CO}_{2}\right\rangle$ :

$\frac{\mathrm{dVC}_{\mathrm{CO}_{2}}}{\mathrm{~d} t}=\frac{\mathrm{d}\left\langle\mathrm{CO}_{2}\right\rangle}{\mathrm{d} t} \cdot \mathrm{VC}_{\mathrm{air}}$

In Eq. (4), $\frac{\mathrm{dVC}_{\mathrm{CO}_{2}}}{\mathrm{~d} t}$ has units of flux $\left[\mathrm{mol} \mathrm{m}^{-2} \mathrm{~s}^{-1}\right]$. The column-averaged mixing ratio, $\left\langle\mathrm{CO}_{2}\right\rangle$, may change due either to local surface fluxes, to changes in the tropopause height, or to advection of $\mathrm{CO}_{2}$. If we neglect the influence of advection (an assumption that will turn out to be untenable on short timescales), we can assess the extent to which variations in $\left\langle\mathrm{CO}_{2}\right\rangle$ capture local flux signals. Substituting $\mathrm{VC}_{\text {air }}$ from Eq. (3) with $\mathrm{G}=\mathrm{O}_{2}$ into Eq. (4), we calculate NEE from TCCON observations as:

$\mathrm{NEE}_{\mathrm{FTS}}=\frac{\mathrm{VC}_{\mathrm{O}_{2}}}{\left\langle\mathrm{O}_{2}\right\rangle} \cdot \frac{\Delta\left\langle\mathrm{CO}_{2}\right\rangle}{\Delta \mathrm{t}}$

We calculate $\Delta\left\langle\mathrm{CO}_{2}\right\rangle$ as the four hour difference in $\left\langle\mathrm{CO}_{2}\right\rangle$ centered around solar noon. This method of calculating $\frac{\Delta\left\langle\mathrm{CO}_{2}\right\rangle}{\Delta t}$ maximizes the number of days with adequate temporal coverage; it yields similar results to fitting a line through the data obtained on a single day. $\mathrm{VC}_{\mathrm{O}_{2}}$ is averaged from retrievals within two hours on either side of solar noon, and we use a constant value of 0.20939 for $\left\langle\mathrm{O}_{2}\right\rangle$ (Tohjima et al., 2005). Although the atmospheric concentration of $\mathrm{O}_{2}$ is decreasing by $\sim 4 \mathrm{ppm} \mathrm{yr}^{-1}$ (Manning and Keeling, 2006), this change has a negligible impact on our estimate of NEE. Equation (5) neglects the change in $\mathrm{VC}_{\mathrm{O}_{2}}$, which is at most $0.5 \%$ on four hour timescales.

We test how well NEE inferred from column drawdown represents local biospheric fluxes by comparing Park Falls NEE to eddy covariance flux observations at the same location (discussed in Sect. 2.3). Because the column retrieval is not equally sensitive to all levels of the atmosphere, we must incorporate the averaging kernel of the FTS into the comparison (see Appendix B for more details). Local drawdown impacts the $\mathrm{CO}_{2}$ mixing ratio within the boundary layer. The column observations are less sensitive to $\mathrm{CO}_{2}$ within the boundary layer than to $\mathrm{CO}_{2}$ in the free troposphere (i.e., the surface averaging kernel at $\pm 2 \mathrm{~h}$ of solar noon ranges from 0.7-0.9 over a seasonal cycle, while the averaging kernel within the free troposphere is close to unity). To compare column and flux observations, we damp the observed eddy 


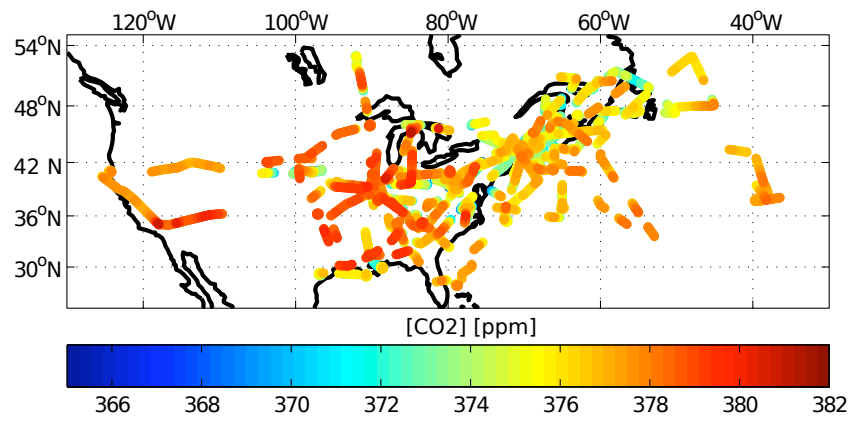

Fig. 2. Flight tracks in the free troposphere $(350-800 \mathrm{hPa})$ during INTEX-NA during July-August 2004. Free tropospheric $\mathrm{CO}_{2}$ is highly variable during these two months.

covariance flux by the surface value of the column averaging kernel, as this is the signature of local fluxes that would be imparted on the observed column. This method is similar to the approach used by Wunch et al. (2009) to analyze diurnal variations in $\left\langle\mathrm{CO}_{2}\right\rangle$ and other greenhouse gases in the Los Angeles basin.

\subsection{Eddy covariance flux data}

Fluxes of $\mathrm{CO}_{2}$, water vapor, virtual temperature, and momentum are measured continuously at 30,122, and $396 \mathrm{~m}$ on the WLEF tower in Park Falls. $\mathrm{CO}_{2}$ and water vapor mixing ratios are measured using infrared gas analyzers (Li-COR Inc., Lincoln, Nebraska, model LI-6262). Virtual temperature and momentum are measured using sonic anemometers (Applied Technologies Inc., Boulder, Colorado, model SATI/3K or Campbell Scientific Inc., Logan, Utah, model CSAT3). High-precision, high-accuracy $\mathrm{CO}_{2}$ mixing ratio measurements are simultaneously recorded at 30,122 , and $396 \mathrm{~m}$ using Li-COR model LI-6251and LI-7000 infrared gas analyzers (Bakwin et al., 1998; Zhao et al., 1997). These measurements are used to calibrate the fast-response infrared gas analyzers and to calculate the rate of change of storage for $\mathrm{CO}_{2}$ (Davis et al., 2003). The eddy covariance instrumentation and methodology is described in detail in Berger et al. (2001) and Davis et al. (2003). Davis et al. (2003) developed an algorithm for preferred NEE that combines measurements at the three levels to maintain a large footprint while avoiding the influence of the clearing around the tower. The footprint of the midday flux measurements within the convective boundary layer is discussed by Wang et al. (2006), and surface layer flux footprints are discussed by many authors (e.g., Horst and Weil, 1992). Flux uncertainties due to changes in the level of the flux measurement and random errors were discussed by Ricciuto et al. (2008). We determine daily average NEE within two hours of solar noon to compare with drawdown in the column. We use data obtained between 2004 and 2009, only on days with both column and eddy covariance data.

\subsection{Aircraft data}

Free tropospheric $\left[\mathrm{CO}_{2}\right]$ data from two field campaigns that had extensive geographic coverage are used in this analysis. Free tropospheric $\left[\mathrm{CO}_{2}\right]$ data were obtained in situ during the Intercontinental Chemical Transport Experiment (INTEX-NA), a NASA-sponsored aircraft mission in JulyAugust 2004 (Choi et al., 2008). Data were obtained between $28^{\circ}$ and $54^{\circ} \mathrm{N}$ along the flight tracks shown in Fig. 2. Carbon dioxide mixing ratios were determined using a modified LI-COR model 6252 non-dispersive infrared gas analyzer. This dual-cell instrument achieves high precision by measuring the differential absorption between sample air and a calibrated reference gas that is traceable to the WMO primary $\mathrm{CO}_{2}$ standards. The LI-COR-based $\mathrm{CO}_{2}$ sampling system was operated at constant pressure $(333 \mathrm{hPa})$ and temperature $\left(40^{\circ} \mathrm{C}\right)$, and had a precision of $0.07 \mathrm{ppm}$ and accuracy of $0.20 \mathrm{ppm}$ ( $1 \mathrm{~s} / 1-\sigma$ precision, $1-\sigma$ accuracy). Experimental procedures are described in detail by Vay et al. (2003).

Free tropospheric $\left[\mathrm{CO}_{2}\right]$ was measured during the first $\mathrm{HI}-$ APER Pole-to-Pole Observations (HIPPO 1) campaign in January 2009 over the Pacific (Wofsy et al., 2011). [ $\left[\mathrm{CO}_{2}\right]$ was measured between $80^{\circ} \mathrm{N}$ and $67^{\circ} \mathrm{S}$ using three instruments, two Li-COR non-dispersive infrared gas analyzers as well as a quantum cascade laser system (QCLS) and two flask samplers. In this study, we use only QCLS data, which has precision of $0.02 \mathrm{ppm}$ and accuracy of $0.1 \mathrm{ppm}(1 \mathrm{~s} / 1-\sigma$ precision, 1- $\sigma$ accuracy). During HIPPO $1,\left[\mathrm{CO}_{2}\right]$ was sampled in the free troposphere over a series of vertical profiles. We limit our analysis to those profiles that exceed $500 \mathrm{hPa}$ in vertical extent and have a pressure floor of at least $900 \mathrm{hPa}$. We append stratospheric $\mathrm{CO}_{2}$ profiles to the observed vertical profiles based on the TCCON a priori $\mathrm{CO}_{2}$ profile for the sampled locations, and then integrate these profiles to determine the column mixing ratio. The locations of the profiles obtained in the Northern Hemisphere are shown in Fig. 3.

For both campaigns, the cited accuracy is relative to the WMO standards. It is worth noting that actual limits to accuracy are in the form of non-random, systematic biases. Expression of accuracy as a 1- $\sigma$ value represents a judgment based on intercomparison activities that these biases are less than or equal to the given values $68 \%$ of the time. During both INTEX-NA and HIPPO 1, profile measurements were obtained at TCCON sites. These profiles are among the data used to calibrate TCCON $\left\langle\mathrm{CO}_{2}\right\rangle$ data (Washenfelder et al., 2006; Wunch et al., 2010).

\subsection{Simulations with a transport model}

We compare variations in observed $\left\langle\mathrm{CO}_{2}\right\rangle$ against simulations from KWS11. Briefly, these simulations use the AM2 general circulation model (GCM) of NOAA's Geophysical Fluid Dynamics Laboratory, a free-running GCM with prescribed sea surface temperatures (Anderson et al., 2004). We run the model at $2^{\circ}$ latitude by $2.5^{\circ}$ longitude resolution with 


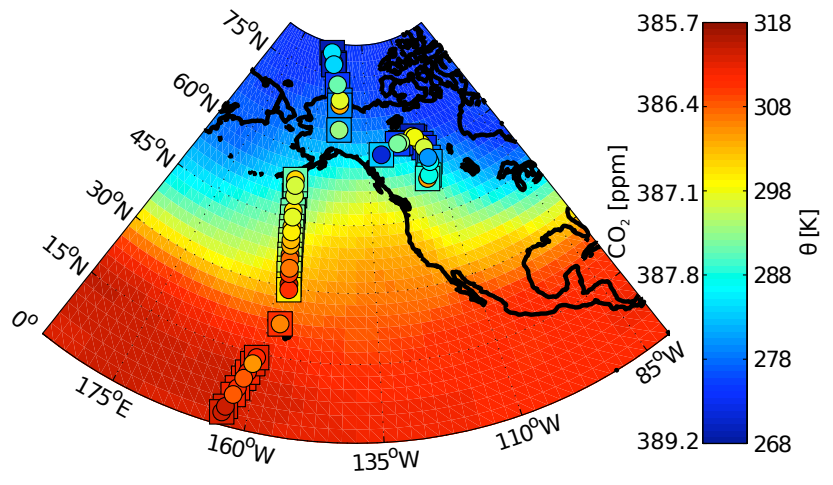

Fig. 3. HIPPO partial $\mathrm{CO}_{2}$ columns overlaid on January monthly mean potential temperature, $\theta$. The inner circle is colored by $\left\langle\mathrm{CO}_{2}\right\rangle$, while the outer square is colored by $\theta$ at $700 \mathrm{hPa}$ at the time the profile was acquired.

25 vertical levels. As land surface fluxes in the GCM, we use monthly NEE (balanced to give zero annual mean) from the climatological mean Carnegie Ames Stanford Approach (CASA) simulation (Randerson et al., 1997). These are the same CASA fluxes as in Olsen and Randerson (2004) with NEE representing the residual of monthly net primary production (NPP) and respiration fluxes. NEE has been redistributed at $3 \mathrm{~h}$ resolution based on the year 2000 meteorology to capture diurnal and synoptic flux patterns, but the monthly mean flux at any grid box is equal to the climatological mean. These fluxes provide a good estimate of the expected patterns in atmospheric $\left\langle\mathrm{CO}_{2}\right\rangle$ in an average year, even though our simulations do not correspond to any given year. CASA biospheric fluxes are commonly used by the carbon cycle community and are the basis for prior fluxes in many inversion simulations including TransCom (Gurney et al., 2002) and CarbonTracker (Peters et al., 2007), which uses CASA-GFEDv2 for its prior (van der Werf et al., 2006).

Ocean surface fluxes are prescribed as monthly-mean fluxes derived from surface ocean $p \mathrm{CO}_{2}$ data (Takahashi et al., 2002). These ocean fluxes represent an annual and global mean sink of atmospheric $\mathrm{CO}_{2}$ of $\sim 1.4 \mathrm{Pg} \mathrm{Cyr}^{-1}$. A more recent version of these fluxes is available, but our results are not sensitive to variations in oceanic fluxes. We use annual mean fossil emissions with net global emissions of $\sim 5.5 \mathrm{Pg} \mathrm{Cyr}^{-1}$ (Andres et al., 1996). These emissions are determined from self-reported fuel consumption at the national level (Marland and Rotty, 1984) and are converted to regional fluxes proportional to local population density. We also use updated fossil fluxes determined at monthly time resolution from 2004-2007 (Gregg and Andres, 2008; Gregg et al., 2009; Andres et al., 2011) to test the sensitivity of the column to these larger and temporally varying parameterization of the fossil fluxes.

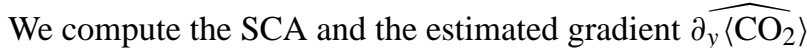
for the model gridboxes corresponding to TCCON sites to compare with the observations, incorporating the FTS averaging kernel (Appendix B).

As shown in KWS11, biospheric fluxes impart the largest variations in $\left\langle\mathrm{CO}_{2}\right\rangle$. We therefore focus our comparisons of observed $\left\langle\mathrm{CO}_{2}\right\rangle$ against three simulations with variations in biospheric fluxes: CASA exchange, boreal amplified CASA exchange, and boreal amplified CASA exchange with an early growing season onset as described in KWS11. In the boreal amplified simulations, NEE is amplified by a Gaussian weighting function centered at $55^{\circ} \mathrm{N}$ with a peak value of 1.5 that decays to unity over a standard deviation of $10^{\circ}$. Integrated over $45-65^{\circ} \mathrm{N}$, NEE is increased by $40 \%$; integrated over the Northern Hemisphere, NEE is increased by $30 \%$. In the boreal amplified simulations with early growing season onset, we use NEE with the boreal amplification described above, but add July NEE to May NEE between $50-60^{\circ} \mathrm{N}$, which changes the sign of May NEE, thus converting a net source to a net sink and moving the onset of the growing season earlier by one month. We focus on sensitivity simulations with perturbed boreal fluxes because the large seasonality of boreal NEE has a large imprint on the seasonal cycle in $\mathrm{CO}_{2}$ (KWS11, Randerson et al., 1997); the KWS simulations show that changing NEE in the subtropics or midlatitudes has a small effect on the SCA of $\left\langle\mathrm{CO}_{2}\right\rangle$.

To describe seasonally resolved TransCom flux inversion results, the land flux amplitude is defined as $12 \cdot\left(\overline{\mathrm{NEE}}_{\text {Jun-Aug }}-\overline{\mathrm{NEE}}_{\mathrm{Oct}-\mathrm{Mar}}\right)$, with optimized flux amplitudes ranging from 21 to $31 \mathrm{Pg} \mathrm{C} \mathrm{yr}^{-1}$ (Gurney et al., 2004). Northern Hemisphere temperate and boreal terrestrial regions, roughly consistent with land area north of $20^{\circ}$, are included in this calculation. When we apply this definition to the prescribed fluxes described above, CASA fluxes have a flux amplitude of $27 \mathrm{Pg} \mathrm{Cyr}^{-1}$, boreal amplified CASA

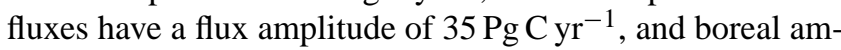
plified CASA fluxes with early growing season onset have a flux amplitude of $37 \mathrm{Pg} \mathrm{C} \mathrm{yr}^{-1}$.

\section{Results}

\subsection{Diurnal variations}

Diurnal variations in observed $\left\langle\mathrm{CO}_{2}\right\rangle$ are small and influenced by a large spatial footprint. At Park Falls, the change in $\left\langle\mathrm{CO}_{2}\right\rangle$ during the summer growing season is $\sim 2 \mathrm{ppm}$ within a given day (Fig. 4). Although this change is small in comparison to diurnal variations at the surface, it is larger than the change predicted in the total column predicted by the simulations in Olsen and Randerson (2004). NEE inferred from column drawdown (Eq. 5) shows little correlation with NEE inferred from eddy covariance on daily timescales (Fig. 5a). A regression of NEE from column drawdown against NEE from eddy covariance on individual days yields a slope of $0.9 \pm 0.3$, an intercept of $-5 \pm 2 \mu \mathrm{mol} \mathrm{m}^{-2} \mathrm{~s}^{-1}$, and an $R^{2}$ of 0.11 . Consistent with this large scatter, KWS11 show that 


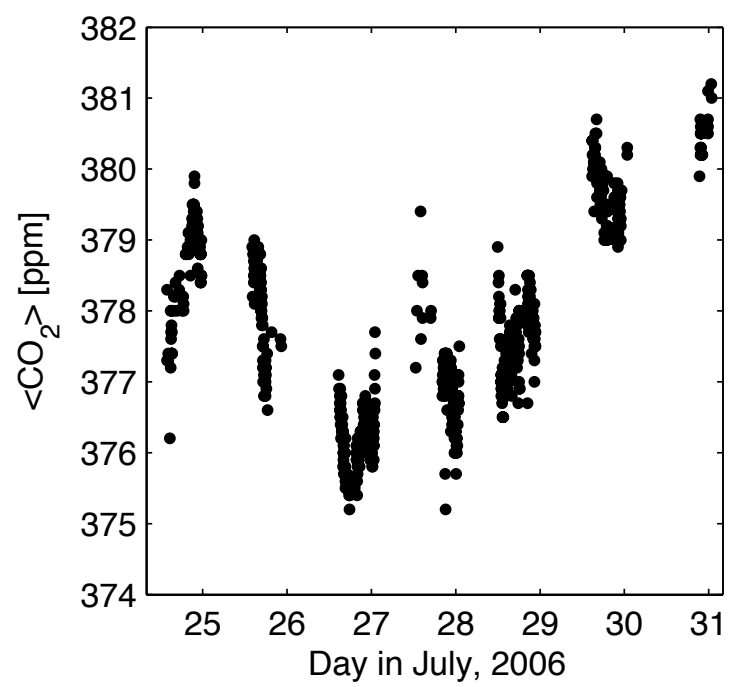

Fig. 4. Daily drawdown in $\left\langle\mathrm{CO}_{2}\right\rangle$ at Park Falls during one week in July 2006. Within one day, $\left\langle\mathrm{CO}_{2}\right\rangle$ changes by $\sim 2 \mathrm{ppm}$.

diurnal variations in simulated $\left\langle\mathrm{CO}_{2}\right\rangle$ are only weakly correlated with the underlying flux.

Although the regional flux signal is not apparent in the total column variations on daily timescales, it does become more apparent when we aggregate NEE on weekly and monthly timescales (Fig. 5b, c). We use a fit that accounts for the standard error of the mean in both eddy covariance NEE and column NEE over the aggregated time period (York et al., 2004). The slopes are $1.5 \pm 0.2$ for the weekly mean data and $1.5 \pm 0.2$ for monthly mean data, and the fits have a negative intercept of $-4.9 \pm 0.8 \mu \mathrm{mol} \mathrm{m}^{-2} \mathrm{~s}^{-1}$ for weekly mean data and $-4.3 \pm 0.7 \mu \mathrm{mol} \mathrm{m}^{-2} \mathrm{~s}^{-1}$ for monthly mean data. The weighted $R^{2}$ values of 0.94 and 0.86 for weekly and monthly data account for the standard error of the mean in the datasets and are much improved relative to the daily comparison. The larger NEE inferred from the FTS column may be attributable to column drawdown having a larger footprint. Regional studies have shown divergent estimates for NEE in the area around Park Falls using several bottom-up and topdown methods (Desai et al., 2010). We have confirmed that the offset between NEE from column drawdown and from eddy covariance is not due to seasonal uptake by removing the seasonal trend from $\left\langle\mathrm{CO}_{2}\right\rangle$ before determining the diurnal drawdown in the column. Neither the slope nor the intercept are significantly affected.

While horizontal and vertical advection make a negligible contribution to daytime NEE determined from eddy covariance (Wang et al., 2005; Yi et al., 2000), our results confirm that horizontal advection does have a large influence on variations in the column even over four hours. We attribute the poor comparison of column drawdown and local NEE on daily timescales to the neglect of advection in Eq. (5). Figure 6 shows two $\left[\mathrm{CO}_{2}\right]$ profiles obtained over Park Falls

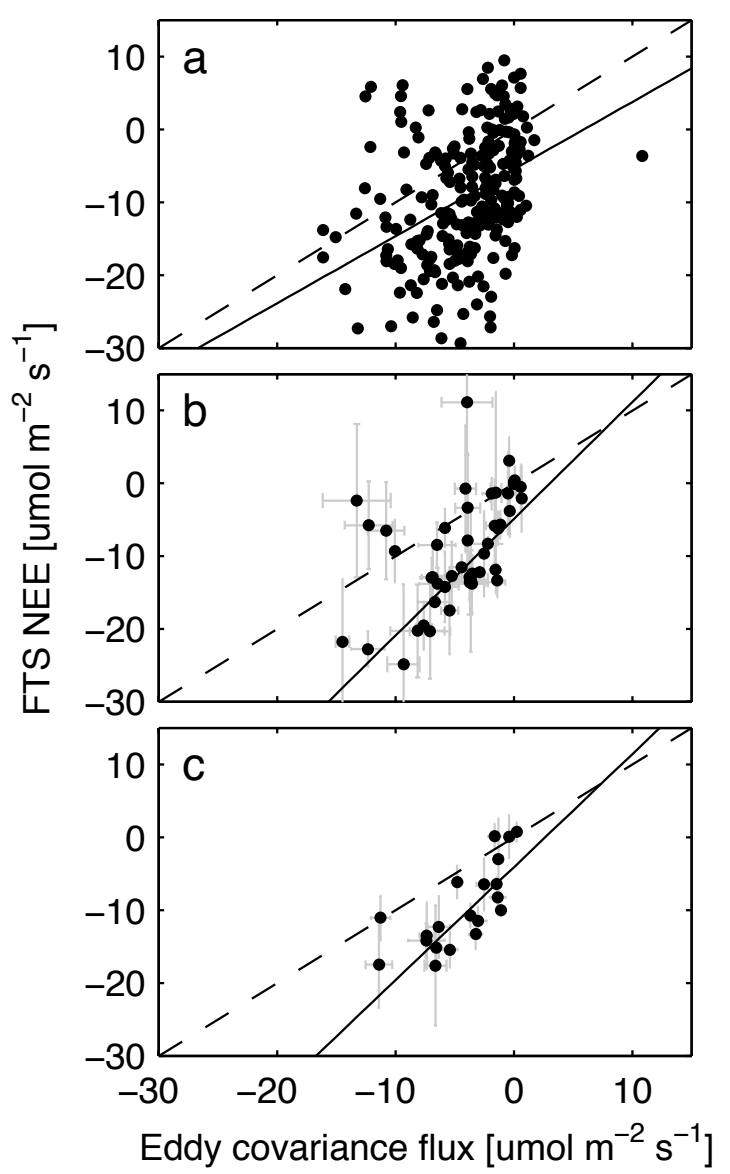

Fig. 5. Comparison between NEE calculated from drawdown in the total column and NEE infered from eddy covariance measurements at Park Falls, Wisconsin. Drawdown in the column is calculated over a $4 \mathrm{~h}$ period symmetric about solar noon. Eddy covariance fluxes are averaged over the same time period. (a) NEE calculated each day for which data are available. (b) Data aggregated by week of year. (c) Data aggregated for each month. The dashed line represents the 1:1 line, while the solid line represents the best fit to the data.

on 15 July 2004 during INTEX-NA. Although the two profiles were obtained only three hours apart, a frontal system moved through the region and the free tropospheric $\left[\mathrm{CO}_{2}\right]$ above $5 \mathrm{~km}$ increased by $\sim 5 \mathrm{ppm}$ during this time. The drawdown of boundary layer $\left[\mathrm{CO}_{2}\right]$ over the same three hours is much smaller. Only when we aggregate column drawdown and eddy covariance fluxes over several synoptic cycles is the influence of the large synoptic variability in free tropospheric $\left[\mathrm{CO}_{2}\right]$ reduced sufficiently to reveal a robust relationship between column drawdown and local eddy covariance fluxes (Fig. 5b-c). We have investigated whether there is a relationship between the mismatch in NEE derived from the two measurements and meteorological variables such as wind speed, wind direction, and diurnal changes in pressure and temperature. We do not find correlations between 


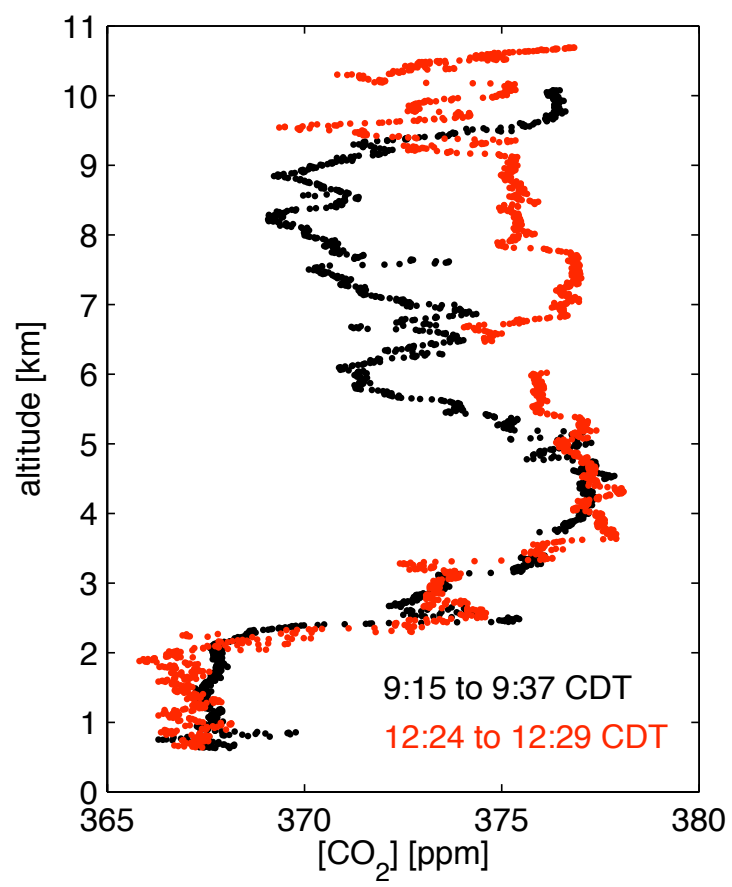

Fig. 6. Two profiles obtained above Park Falls on 15 July 2004 within three hours during the INTEX-NA campaign. A frontal system moved through the region between the profiles, leading to a $\sim 5 \mathrm{ppm}$ increase in free tropospheric $\left[\mathrm{CO}_{2}\right]$ between $5-9 \mathrm{~km}$. The decrease in boundary layer $\left[\mathrm{CO}_{2}\right]$ is notably smaller.

diagnostics for advection and mismatch in NEE. Modelling tools such as back trajectory analysis originating from multiple levels in the column may prove helpful in diagnosing changes in $\left\langle\mathrm{CO}_{2}\right\rangle$ on sub-diurnal timescales, but they require accurate background $\left\langle\mathrm{CO}_{2}\right\rangle$ distributions to be useful.

In summary, the comparison between drawdown in $\left\langle\mathrm{CO}_{2}\right\rangle$ and eddy covariance flux confirms that while regional information is contained in column observations, these regional flux signals are obscured by larger-scale variations in $\left\langle\mathrm{CO}_{2}\right\rangle$ even on short timescales.

\subsection{Horizontal gradients as sources of synoptic variations in $\left\langle\mathrm{CO}_{2}\right\rangle$}

Advection leaves a notable signature on $\left\langle\mathrm{CO}_{2}\right\rangle$ at seasonal and shorter timescales. Figure 7 illustrates the relationship between synoptic-scale variability and north-south gradients in $\left\langle\mathrm{CO}_{2}\right\rangle$ at Park Falls and Lamont, two North American TCCON sites that are separated by $9^{\circ}$ latitude. Outside the growing season, the two timeseries essentially overlap, indicative of a small meridional $\left\langle\mathrm{CO}_{2}\right\rangle$ contrast between the two sites. At the onset of the growing season (May), the two timeseries diverge; the larger decrease in $\left\langle\mathrm{CO}_{2}\right\rangle$ at Park Falls results in a significant mean contrast $(\sim 3 \mathrm{ppm})$ between the two sites. During the period of divergence, the variability at each site increases noticeably. This variability is a direct re-

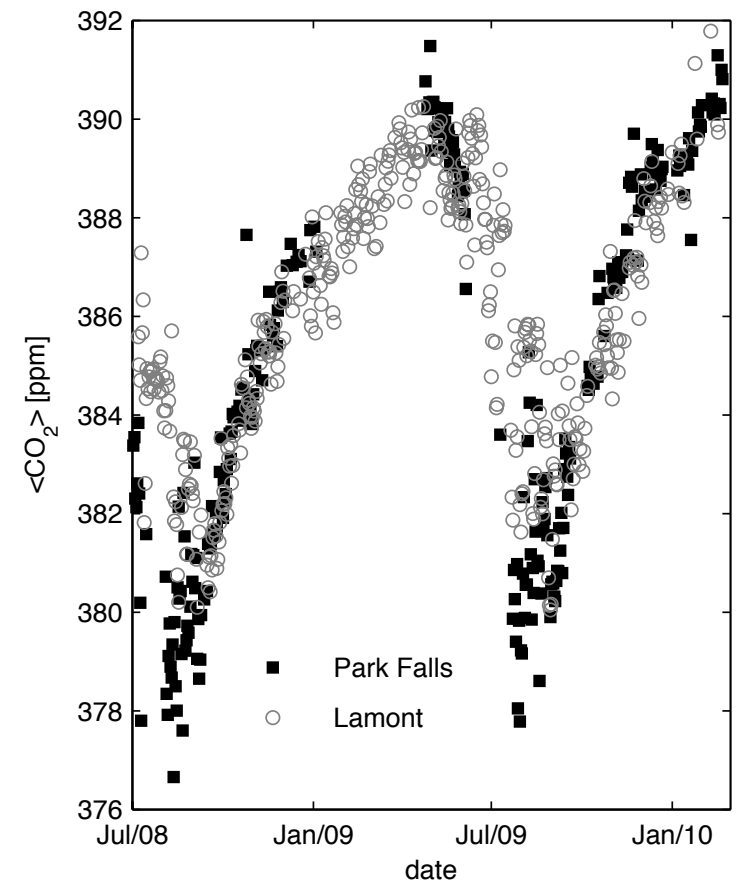

Fig. 7. Fifteen months of daily median $\left\langle\mathrm{CO}_{2}\right\rangle$ at Park Falls and Lamont. We see the impact of large-scale gradients in these two timeseries: the records are similar outside the growing season (when north-south gradient in $\mathrm{CO}_{2}$ is small) and the records diverge during the growing season (June-August) when $\mathrm{CO}_{2}$ is drawn down in the north. When the north-south gradient is larger, synoptic scale variations in daily median $\left\langle\mathrm{CO}_{2}\right\rangle$ are larger, reflecting the fact that variations arise from advection of gradients.

sult of the increased meridional gradient and weather systems advecting air to each site from the north and south. Although the median $\left\langle\mathrm{CO}_{2}\right\rangle$ is quite different at the two sites during the growing season, there is overlap within the observed variability: higher $\left\langle\mathrm{CO}_{2}\right\rangle$ values at Park Falls are similar the lower $\left\langle\mathrm{CO}_{2}\right\rangle$ values at Lamont.

We exploit the variability in daily median $\left\langle\mathrm{CO}_{2}\right\rangle$ and free tropospheric potential temperature, $\theta$, to infer a north-south gradient representative of large spatial scales. Figure 8 shows daily median $\left\langle\mathrm{CO}_{2}\right\rangle$ at Park Falls, Wisconsin for one month in summer 2006. Day-to-day variations are large $(\sim 5 \mathrm{ppm}$ within one week), approximately half the amplitude of the seasonal cycle. These variations correlate with changes in $\theta$ at $700 \mathrm{hPa}$. Cold air (low $\theta$ ) from the north has lower $\left\langle\mathrm{CO}_{2}\right\rangle$; warm air (high $\theta$ ) from the south has higher $\left\langle\mathrm{CO}_{2}\right\rangle$. During the growing season, approximately one-third of the variations in $\left\langle\mathrm{CO}_{2}\right\rangle$ at Park Falls can be accounted for by variations in $\theta\left(R^{2}=0.34\right)$. We estimate Northern Hemisphere summer $\partial_{y} \widehat{\left\langle\mathrm{CO}_{2}\right\rangle}$ at Park Falls to be $1.1 \mathrm{ppb} \mathrm{km}^{-1}$ and at Lamont to be $1.3 \mathrm{ppb} \mathrm{km}^{-1}$ (Table 2). 


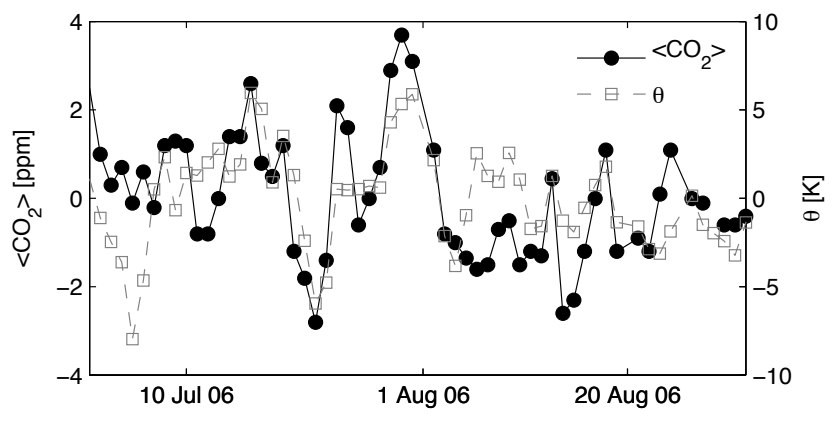

Fig. 8. Daily median $\left\langle\mathrm{CO}_{2}\right\rangle$ at Park Falls for two months in summer 2006 overlaid with daily mean potential temperature, $\theta$, from NCEP reanalysis sampled at Park Falls at $700 \mathrm{hPa}$. The mean $\left\langle\mathrm{CO}_{2}\right\rangle$ and mean $\theta$ for the two-month period have been subtracted from the respective time series. Within a week, daily median $\left\langle\mathrm{CO}_{2}\right\rangle$ varies by up to $5 \mathrm{ppm}$. $\left\langle\mathrm{CO}_{2}\right\rangle$ and $\theta$ covary because both have strong northsouth gradients and variations arise from advection of these gradients.

In Fig. 9, we show TCCON $\left\langle\mathrm{CO}_{2}\right\rangle$ in July and August as a function of meridional displacement relative to Park Falls. A negative meridional displacement signifies that an airmass originated south of Park Falls, and a positive displacement that the airmass originated north of Park Falls. Variations in $\left\langle\mathrm{CO}_{2}\right\rangle,\left\langle\mathrm{CO}_{2}\right\rangle^{\prime}$, are determined relative to annual mean $\left\langle\mathrm{CO}_{2}\right\rangle$ at Lauder. Negative $\left\langle\mathrm{CO}_{2}\right\rangle^{\prime}$ values, such as those at Park Falls and Bialystok, indicate that during Northern Hemisphere summer, $\left\langle\mathrm{CO}_{2}\right\rangle$ is consistently lower than at Lauder. The $\left\langle\mathrm{CO}_{2}\right\rangle^{\prime}$ values at Lamont are centered around zero, indicating that summer mean $\left\langle\mathrm{CO}_{2}\right\rangle$ is similar at Lamont and Lauder. The range of $\left\langle\mathrm{CO}_{2}\right\rangle$ sampled at sites between $34^{\circ}$ and $53^{\circ} \mathrm{N}$ is $\sim 9$ ppm corresponding to meridional displacements between $3000 \mathrm{~km}$ south and $1500 \mathrm{~km}$ north of Park Falls at $46^{\circ} \mathrm{N}$.

\subsection{Free tropospheric data from aircraft}

Free tropospheric $\left[\mathrm{CO}_{2}\right]$ between $350-800 \mathrm{hPa}$ measured during the INTEX-NA mission show a similar correlation with $\theta$. We obtained coincident $700 \mathrm{hPa} \theta$ from the NCEP North American Regional Reanalysis (Mesinger et al., 2006) by interpolation along the flight tracks, which yields the same results as using $\theta$ sampled on the aircraft interpolated to $700 \mathrm{hPa}$. The in situ data show a positive correlation of $\mathrm{CO}_{2}$ with $\theta$ throughout the free troposphere (Fig. 10a). The correlation between $\left[\mathrm{CO}_{2}\right]$ and $\theta$ is much stronger than that between $\mathrm{CO}_{2}$ and latitude because synoptic systems passing through the sampled regions obscure the mean north-south gradient (Fig. 10b).

We can quantitatively estimate the north-south gradient in $\mathrm{CO}_{2}$ from INTEX-NA data using the same approach we use for column data. We designate three free tropospheric layers between $350-800 \mathrm{hPa}$ and a fourth bin for the boundary layer (between the surface and $800 \mathrm{hPa}$ ). We recenter $\left[\mathrm{CO}_{2}\right]$ and

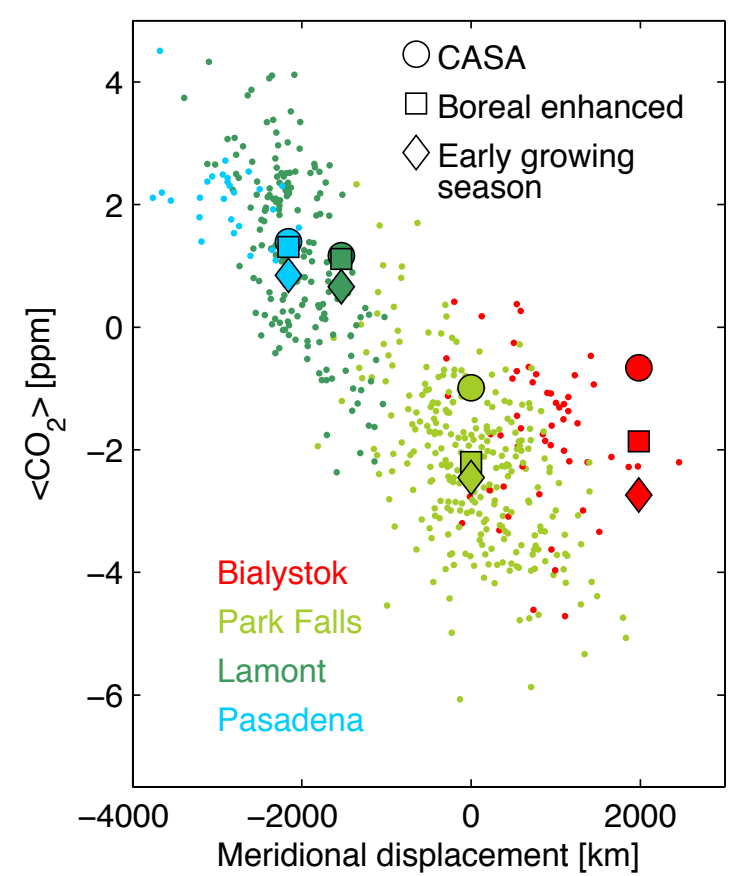

Fig. 9. July-August $\left\langle\mathrm{CO}_{2}\right\rangle^{\prime}$ from four Northern Hemisphere TCCON sites plotted against its meridional displacement relative to Park Falls, determined from variations in $\theta$ (small circles). A positive meridional displacement indicates a northerly airmass. Also plotted are the July-August mean $\left\langle\mathrm{CO}_{2}\right\rangle$ for TCCON sites from three AM2 simulations with modified NEE. The $\left\langle\mathrm{CO}_{2}\right\rangle$ values plotted are referenced to the $\left\langle\mathrm{CO}_{2}\right\rangle$ at Lauder, New Zealand. $\left\langle\mathrm{CO}_{2}\right\rangle$ from a simulation using CASA NEE (large circles) underestimates the north-south gradient among the TCCON sites. Amplified boreal fluxes (squares) and amplified boreal fluxes with an early growing season onset (diamonds) better capture the north-south gradient during summer.

$\theta$ by the mean value within each pressure bin and fit a line to relate variations in $\left[\mathrm{CO}_{2}\right]$ to variations in $\theta$. The resulting slopes are weighted by the atmospheric mass in each pressure bin and summed. We then normalize by the meridional gradient in $\theta$ at $45^{\circ} \mathrm{N}$ to determine the meridional gradient in $\mathrm{CO}_{2}$. The resulting estimate of north-south gradient agrees very well with the gradient estimated at Park Falls and Lamont (Table 2).

Analysis of Northern Hemisphere HIPPO data obtained in January 2009, primarily over the north Pacific, show a northsouth gradient that has reversed sign relative to the summer gradient. In Fig. 3, we map January 2009 mean $700 \mathrm{hPa} \theta$ contours from NCEP reanalysis, and overlay HIPPO partial column $\left\langle\mathrm{CO}_{2}\right\rangle$ with $\theta$ at the time of the observation. The observed $\left\langle\mathrm{CO}_{2}\right\rangle$ and $\theta$ are generally anti-correlated, as expected for winter when respiration dominates photosynthesis at high northern latitudes, setting up a positive gradient in biospheric $\left\langle\mathrm{CO}_{2}\right\rangle$. The calculated gradient is $-0.2 \pm 0.1 \mathrm{ppb} \mathrm{km}^{-1}$, determined from 42 partial columns 
Table 2. Estimated meridional gradient $\left[\mathrm{ppb} \mathrm{km}^{-1}\right]$ in $\left\langle\mathrm{CO}_{2}\right\rangle$ during the Northern Hemisphere summer growing season determined from TCCON sites and in free tropospheric $\left[\mathrm{CO}_{2}\right]$ from INTEX-NA data compared to AM2 simulations.

\begin{tabular}{lrrrr}
\hline Location & Observations & CASA & Boreal amplified & $\begin{array}{r}\text { Early growing } \\
\text { season }\end{array}$ \\
\hline Park Falls & $1.1 \pm 0.3$ & $0.6 \pm 0.1$ & $0.9 \pm 0.2$ & $1.1 \pm 0.3$ \\
Lamont & $1.3 \pm 0.6$ & $0.4 \pm 0.2$ & $0.7 \pm 0.3$ & $0.7 \pm 0.3$ \\
INTEX & $1.1 \pm 0.2$ & $0.7 \pm 0.2$ & $1.1 \pm 0.2$ & $1.2 \pm 0.3$ \\
\hline
\end{tabular}

in the Northern Hemisphere. Figure 11 shows HIPPO free tropospheric $\left[\mathrm{CO}_{2}\right]$ (between $350-800 \mathrm{hPa}$ ) plotted against observed $\theta$ interpolated to $700 \mathrm{hPa}$; between $30-60^{\circ} \mathrm{N}$, the $\left[\mathrm{CO}_{2}\right]$ contrast is only $2 \mathrm{ppm}$, smaller than that during INTEX-NA during the Northern Hemisphere growing season. Co-plotted are bandpass filtered $\left\langle\mathrm{CO}_{2}\right\rangle$ and $\theta$ variations obtained during January 2009 at the Park Falls and Lamont TCCON observatories. The $\left\langle\mathrm{CO}_{2}\right\rangle$ meridional gradient is consistent with the gradient in free tropospheric $\left[\mathrm{CO}_{2}\right]$ measured during HIPPO.

In summary, these aircraft data demonstrate that the covariation between TCCON $\left\langle\mathrm{CO}_{2}\right\rangle$ and $\theta$ reflects large-scale spatial gradients. Free tropospheric $\mathrm{CO}_{2}$ observed during aircraft campaigns can be used to directly calculate spatial gradients, but such campaigns are of limited duration and spatial extent.

\subsection{Comparison with models}

The SCA in $\left\langle\mathrm{CO}_{2}\right\rangle$ is underestimated throughout the Northern Hemisphere in AM2 with CASA NEE as a boundary condition. Table 1 shows that the SCA at all four Northern Hemisphere TCCON sites is underestimated in CASA simulations by 25-35\%, a finding consistent with Yang et al. (2007) and Nakatsuka and Maksyutov (2009). There is substantial interannual variability in the SCA at TCCON sites with multiple years of data. We report the median SCA and standard deviation for Park Falls, Lamont, and Lauder. For Bialystok and Pasadena, the data record contains only one complete seasonal cycle. We have averaged five seasonal cycles from AM2 to estimate a climatological mean SCA for each site. Our simulations ignore interannual variability in fluxes, but they show that for an average year, CASA underestimates column SCA in Northern Hemisphere midlatitudes. Figure 12a shows the seasonal cycle in observed $\left\langle\mathrm{CO}_{2}\right\rangle$ at four Northern Hemisphere TCCON sites compared to $\left\langle\mathrm{CO}_{2}\right\rangle$ from AM2 with underlying CASA biospheric and standard ocean and fossil fluxes. At all Northern Hemisphere sites, the amplitude is smaller in AM2 than in the observations; the $\mathrm{y}$-axis reflects the offset from annual mean Lauder $\left\langle\mathrm{CO}_{2}\right\rangle$.

We have investigated whether sampling biases could account for the discrepancy between the observed and simulated seasonal cycle amplitudes. Although the TCCON data
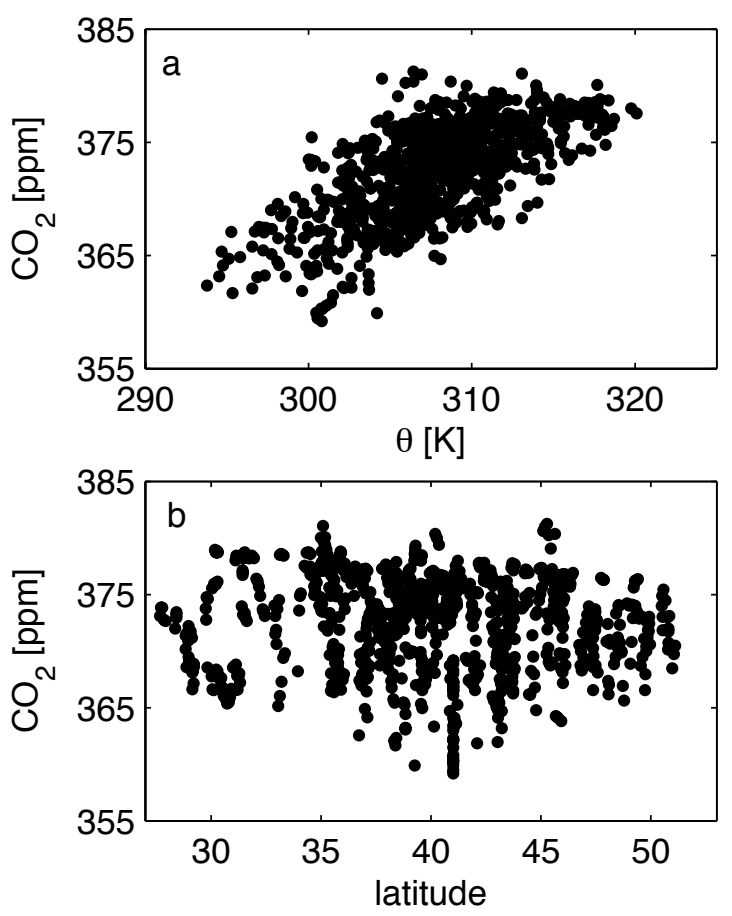

Fig. 10. Free tropopsheric $\left[\mathrm{CO}_{2}\right]$ measured during INTEX-NA plotted against (a) $\theta$ at $700 \mathrm{hPa}$ determined from regional reanalysis data and (b) latitude. $\left[\mathrm{CO}_{2}\right]$ better correlates with potential temperature because synoptic activity obscures the north-south gradient while a dynamical coordinate reveals it.

have been calibrated, we expect that any bias between the sites, or at a single site over a seasonal cycle, would be primarily attributable to retrieval bias associated with the solar zenith angle at which the observations are obtained. To estimate the potential error due to varying solar zenith angle, we average TCCON data obtained only between $60^{\circ}-70^{\circ}$ solar zenith angle. The SCA values change by at most $0.1 \mathrm{ppm}$ at all sites. This suggests that biases in the estimated SCA due to observational biases are small.

We have also investigated the potential bias in the comparison due to the fact that we use daily mean AM2 output to calculate SCA. If instead we analyze hourly $\left\langle\mathrm{CO}_{2}\right\rangle$ output for one model year, SCA changes only by -0.1 to $0.2 \mathrm{ppm}$ using daylight-only $\left\langle\mathrm{CO}_{2}\right\rangle$, a small difference relative to the 


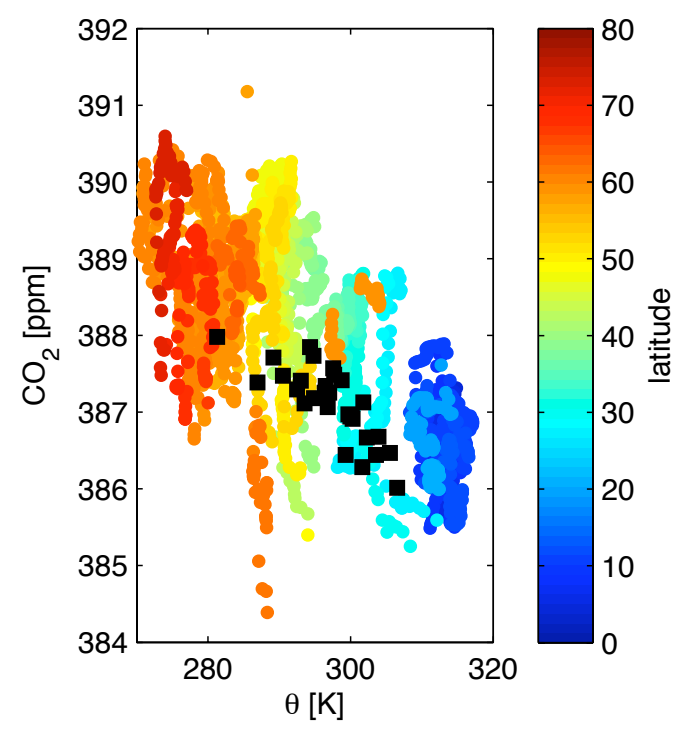

Fig. 11. Free tropopsheric $\left[\mathrm{CO}_{2}\right]$ measured during HIPPO-1 plotted against local $\theta$ and colored by latitude. The contrast across the entire Northern Hemisphere is smaller during winter than the contrast across only the midlatitudes during summer (Fig. 9). Variations in $\left\langle\mathrm{CO}_{2}\right\rangle$ at Lamont and Park Falls during the campaign show a similar north-south gradient (black squares).

disagreement between the simulated and observed seasonal cycle amplitude at TCCON sites.

We also tested the potential bias in the comparison due to the fact that TCCON data are only obtained when the sun is not obscured by clouds. We limit sampling in AM2 to days in which the cloud fraction in the $2^{\circ}$ by $2.5^{\circ}$ gridbox corresponding to each TCCON site is less than $70 \%$. This cloud filter removes $\sim 80 \%$ of days in winter and $\sim 25 \%$ of days in the summer at Park Falls. Removing cloud-contaminated days decreases the SCA by $\sim 5 \%$ at Park Falls and Lamont, and has little effect at Bialystok and Pasadena, suggesting that sampling the model only under cloud-free conditions would increase the disagreement between AM2 with CASA fluxes and the observations.

The north-south gradient in $\left\langle\mathrm{CO}_{2}\right\rangle$ during summer is underestimated by $\sim 45 \%$ with CASA fluxes. This is evident from $\partial_{y} \widehat{\left\langle\mathrm{CO}_{2}\right\rangle}$ estimated at Park Falls or along INTEX tracks (Table 2), or simply by inspecting the $\left\langle\mathrm{CO}_{2}\right\rangle$ contrast between TCCON sites. At the gridbox corresponding to Park Falls, $\partial_{y} \widehat{\left\langle\mathrm{CO}_{2}\right\rangle}$ in AM2 is only $0.6 \mathrm{ppb} \mathrm{km}^{-1}$, compared with $1.1 \mathrm{ppb} \mathrm{km}^{-1}$ determined from the data. For Lamont, $\partial_{y} \widehat{\left\langle\mathrm{CO}_{2}\right\rangle}$ is only $0.4 \mathrm{ppb} \mathrm{km}^{-1}$, in contrast to $1.3 \mathrm{ppb} \mathrm{km}^{-1}$ determined from the data. When sampling in AM2 is limited to days with less than $70 \%$ cloud cover, the estimated gradients decrease by $\sim 10 \%$. Likewise, the gradient estimated from free tropospheric $\left[\mathrm{CO}_{2}\right]$ sampled in the model along weaker than observed by $35 \%$. The north-south contrast across TCCON sites is also too small, as is evident in Fig. 9.
The large circles represent summer mean $\left\langle\mathrm{CO}_{2}\right\rangle$ sampled in AM2. While the mean Pasadena and Lamont $\left\langle\mathrm{CO}_{2}\right\rangle$ generally agree with the observations, the simulated Northern Hemisphere summer mean $\left\langle\mathrm{CO}_{2}\right\rangle$ is too high farther north.

We tested whether the use of 1990 annual mean fossil fuel $\mathrm{CO}_{2}$ emissions could account for the discrepancy by running AM2 with 2004-2007 monthly mean fossil fuel emissions (Andres et al., 2011). At all four Northern Hemisphere TCCON sites, including urban Pasadena, the SCA changes by less than $0.1 \mathrm{ppm}$ when accounting for seasonality in the fluxes. Fossil fuel emissions in 2004-2007 show a more pronounced subtropical source than do 1990 emissions estimates, but the change in the north-south gradient in the column due to updated fluxes is small $\left(<0.04 \mathrm{ppb} \mathrm{km}^{-1}\right.$ at Park Falls).

Simulations with enhanced boreal fluxes better match $\left\langle\mathrm{CO}_{2}\right\rangle$ observations. Figure $12 \mathrm{~b}-\mathrm{c}$ show weekly median timeseries for TCCON data compared to AM2 simulations using boreal-amplified CASA fluxes. The two simulations with amplified boreal fluxes have increased SCAs that bracket the observed column SCAs (Table 1). The simulation with an early onset to the growing season has a growing season net flux somewhat greater than $40 \%$ of the CASA net flux in boreal regions, so overestimation of the SCA is expected. Nevertheless, this simulation better matches the phasing of the observations (Fig. 12b-c), particularly at higher latitude sites. Even sites that are not affected locally by the flux enhancement (i.e., Lamont at $34^{\circ} \mathrm{N}$ ) show an increase in the modeled SCA with the boreal amplified fluxes. The dominant role of the high latitude biosphere in determining the SCA in the subtropics has been noted before (Randerson et al., 1997). There is still a mismatch between simulated and observed $\left\langle\mathrm{CO}_{2}\right\rangle$ at Pasadena due to AM2 having a different mean $\left\langle\mathrm{CO}_{2}\right\rangle$ contrast between Lauder and Pasadena, indicating that the model may be placing Pasadena further into the subtropics dynamically than is realistic.

As the seasonal cycle amplitude increases due to greater summer drawdown in boreal regions in the enhanced simulations, the north-south gradient across TCCON sites grows correspondingly larger (Fig. 9). Increasing boreal uptake during summer has little effect on the mean $\left\langle\mathrm{CO}_{2}\right\rangle$ at Pasadena but reduces mean $\left\langle\mathrm{CO}_{2}\right\rangle$ at Bialystok such that the contrast is in better agreement with the data. At Park Falls, $\partial_{y} \widehat{\left\langle\mathrm{CO}_{2}\right\rangle}$ increases in the boreal-enhanced and borealextended simulations to 0.9 and $1.1 \mathrm{ppb} \mathrm{km}^{-1}$ respectively, in much better agreement with the observations. At Lamont $\partial_{y} \widehat{\left\langle\mathrm{CO}_{2}\right\rangle}$ doubles to $0.7 \mathrm{ppb} \mathrm{km}^{-1}$, but is still too small by $50 \%$ compared to observations. We caution that Lamont may lie too far in the dynamical subtropics in AM2 for accurate calculation of $\partial_{y} \widehat{\left\langle\mathrm{CO}_{2}\right\rangle}$.

\section{Large seasonal flux $=$ small net land sink?}

There is no geobiological reason that seasonality of ecosystem exchange will necessarily have any relationship to 

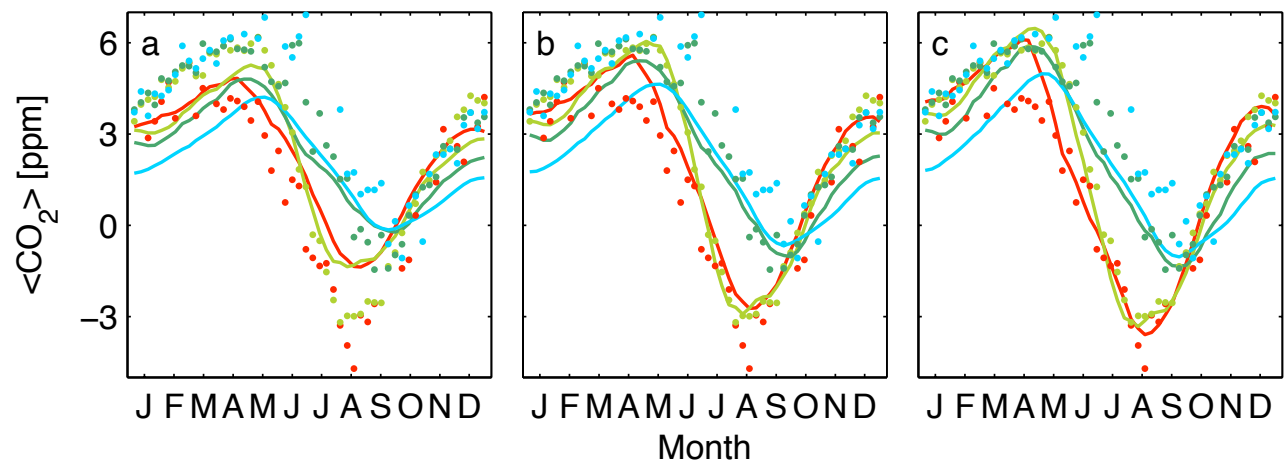

JFMAM J J ASOND

Fig. 12. Detrended weekly median $\left\langle\mathrm{CO}_{2}\right\rangle$ at four Northern Hemisphere TCCON sites (circles) plotted with simulated $\langle\mathrm{CO} 2\rangle$ from $\mathrm{AM} 2$ (solid lines). The simulated $\mathrm{CO}_{2}$ has been smoothed using a two week running mean. The observed and simulated $\left\langle\mathrm{CO}_{2}\right\rangle$ values are referenced to annual mean $\left\langle\mathrm{CO}_{2}\right\rangle$ at Lauder, New Zealand. In each panel, the data are the same, while the simulated seasonal cycles result from (a) CASA net ecosystem exchange, (b) boreal amplified CASA net ecosystem exchange, (c) boreal amplified CASA net ecosystem exchange with an early growing season onset. CASA NEE underestimates the seasonal cycle amplitude in the column at all four sites, while simulations with enhanced boreal exchange better match the data. The colors are the same as in Fig. 1.

the net uptake of carbon by the terrestrial biosphere. Nevertheless, Gurney et al. (2004) have shown a strong negative correlation between the retrieved seasonality and net flux in the TransCom inversions: models that infer large flux seasonality typically infer weak net uptake by the terrestrial biosphere, while those with small flux seasonality infer strong net uptake. This correlation is tied to differences in the transport implementation among models, illustrating the challenge of inferring mass fluxes from concentration data obtained at the surface. In inversions, fluxes are determined by optimizing the mass flux necessary to reproduce the simulated mass gradient. The simulated mass gradient is, however, only constrained by observed variations in boundary layer $\left[\mathrm{CO}_{2}\right]$. When constrained by surface concentration measurements, models that have stronger vertical mixing will yield larger simulated column mass gradients because the observed anomaly at the surface extends deeper into the atmospheric interior whereas models that more slowly advect the concentration anomalies produced by surface fluxes will infer smaller column mass gradients.

So why in the TransCom inversions are the estimates of the seasonality and net flux correlated? In these inversions, the global net uptake of carbon is highly constrained by the observed global growth rate of $\mathrm{CO}_{2}$ and the imposed fossil and land use-change fluxes of $\mathrm{CO}_{2}$ to the atmosphere. The decomposition of the global net flux into oceanic and terrestrial components is ultimately tied to the inferred column gradient in $\mathrm{CO}_{2}$ between the Northern and Southern Hemispheres: a small simulated north-south gradient implies that sinks in the Northern Hemisphere counteract fossil emissions within the Northern Hemisphere. This explains the correlation between the net land flux and the seasonal flux: the models with strong vertical mixing produce larger seasonal fluxes because the expression of these fluxes at the surface is minimized while the expression of these fluxes on the column mass is significant. Such models will also project a larger interhemispheric fossil fuel $\mathrm{CO}_{2}$ column gradient from the observed variations at the surface because these variations extend into the free troposphere. Thus, the inferred Northern Hemisphere net sink is smaller in models with stronger vertical mixing, which pushes the inversion toward a more globally distributed net sink (e.g., in the oceans rather than on land).

The above discussion illustrates the importance of having improved mass constraints for inverse modeling. Densely sampled aircraft profiles provide one such constraint (Stephens et al., 2007; Nakatsuka and Maksyutov, 2009). We show here that measurements of $\left\langle\mathrm{CO}_{2}\right\rangle$ provide another such improvement. In this study, we show using column data that the seasonal fluxes are larger than previously estimated from surface data. In fact, the column derived land flux amplitude $\left(35 \mathrm{Pg} \mathrm{Cyr}^{-1}\right)$ is larger than that from any of the the TransCom inversions (Median: $\sim 26 \mathrm{Pg} \mathrm{C} \mathrm{yr}^{-1}$; Range: $21-$ $31 \mathrm{PgC} \mathrm{yr}^{-1}$ ). The prediction is that because the TransCom models that came closest to the true value (the models with strongest vertical mixing) yielded the smallest net land sink in the Northern Hemisphere, an inversion using additional constraints from the column will likewise produce small estimates for the net Northern Hemisphere land sink. This remains to be confirmed in a proper inversion of both data types.

Reanalysis fluxes from CarbonTracker also suggest greater growing season uptake in the boreal forests than CASA fluxes. Figure 13 shows the zonal mean June-August NEE from CASA and 2008 CarbonTracker biospheric fluxes (Peters et al., 2007). NOAA's CarbonTracker data assimilation system uses CASA-GFEDv2 fluxes as its prior NEE estimate (van der Werf et al., 2006). By assimilating surface and tower $\left[\mathrm{CO}_{2}\right]$ data, CarbonTracker increases growing season NEE, with most of the increase in boreal ecosystems. 


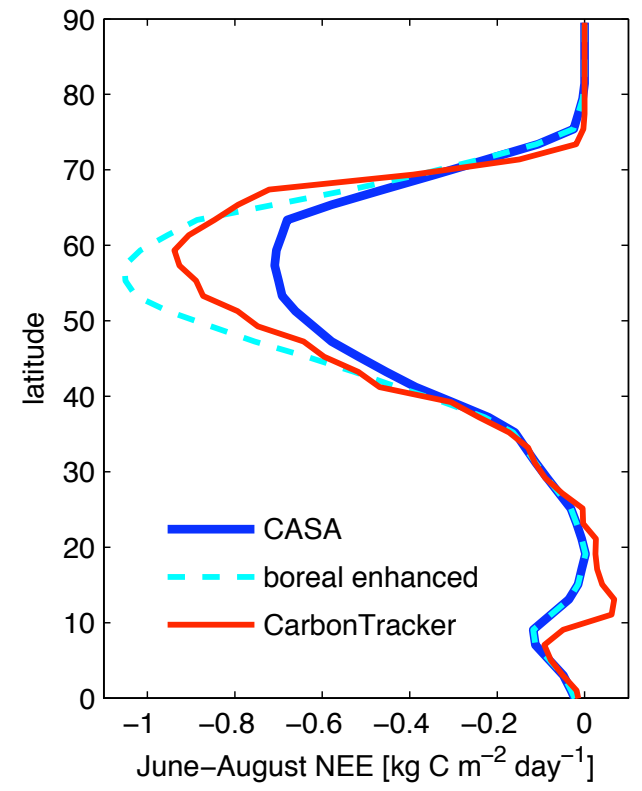

Fig. 13. Zonal mean net ecosystem exchange averaged for JuneAugust from CASA (solid blue), boreal enhanced CASA (dashed cyan) and optimized CarbonTracker for 2008 (solid red). CarbonTracker increases boreal fluxes during its assimilation of boundary layer $\left[\mathrm{CO}_{2}\right]$.

Compared to the CASA NEE used in AM2 simulations, CarbonTracker NEE is greater by $\sim 25 \%$, integrated between 45 and $65^{\circ} \mathrm{N}$ for June through August (and greater by $\sim 15 \%$ relative to the prior CASA-GFEDv2 NEE), with a seasonal flux amplitude of $30 \mathrm{PgC} \mathrm{yr}^{-1}$ compared to $27 \mathrm{PgC} \mathrm{yr}^{-1}$. This high latitude increase to the growing season flux leads to better agreement in $\partial_{y}\left\langle\mathrm{CO}_{2}\right\rangle$ estimated in midlatitudes and SCAs closer but still less than the SCAs in observations and in AM2 simulations with our boreal flux amplification (Table 1). With respect to the partitioning of the net $\mathrm{CO}_{2}$ sink, CarbonTracker yields a net Northern Hemisphere land sink since 2000 of $\sim 2 \mathrm{Pg} \mathrm{Cyr}^{-1}$, approximately one-third of the global (land + ocean) carbon sink. This represents a significant reduction in the contribution of Northern Hemisphere land compared to Gurney et al. (2004), where the mean Northern Hemisphere land sink was $2.4 \mathrm{Pg} \mathrm{C} \mathrm{yr}^{-1}$ relative to a global sink of $2.8 \mathrm{Pg} \mathrm{C} \mathrm{yr}^{-1}$ for the period from 1992-1996.

\section{Conclusions}

Consistent with results from KWS11, TCCON data from Park Falls show that even on hourly timescales, changes in the column are dominated by non-local effects. Diurnal variations in $\left\langle\mathrm{CO}_{2}\right\rangle$ show a relationship with the underlying flux inferred from eddy covariance observations only after averaging over several synoptic cycles.

Midlatitude column $\left\langle\mathrm{CO}_{2}\right\rangle$ data and its correlation with synoptic-scale variations in $\theta$ can be used to estimate the large-scale gradient in $\left\langle\mathrm{CO}_{2}\right\rangle$. We estimate the north-south gradient during the growing season at Park Falls to be $1.1 \mathrm{ppb} \mathrm{km}^{-1}$, equivalent to a $\sim 4 \mathrm{ppm}$ contrast across $30^{\circ}$ of latitude. Free tropospheric $\left[\mathrm{CO}_{2}\right]$ data obtained during INTEX-NA are consistent with this meridional gradient. We use $\theta$ to define a meridional displacement scale and show that variations in $\left\langle\mathrm{CO}_{2}\right\rangle$ sampled at Northern Hemisphere midlatitude TCCON sites are primarily driven by advection of airmasses that originate north and south of the observatories. Rather than obscure flux signatures, these synoptic scale variations reveal the meridional gradient in surface fluxes.

While variations in $\left\langle\mathrm{CO}_{2}\right\rangle$ primarily reflect large scale gradients, variations in boundary layer $\left[\mathrm{CO}_{2}\right]$ reflect both local fluxes and entrainment of free tropospheric $\mathrm{CO}_{2}$ into the boundary layer. Therefore, it is possible to alias the largescale component of boundary layer variability into local surface fluxes when attempting to optimize surface fluxes based only on boundary layer observations. Our findings suggest that by combining $\left\langle\mathrm{CO}_{2}\right\rangle$ and boundary layer $\mathrm{CO}_{2}$ observations, we can properly attribute variability to local or largescale influences based on the correlation of $\left\langle\mathrm{CO}_{2}\right\rangle$ with $\theta$. We expect that more robust flux estimates can be inferred using this approach.

TCCON data suggest that Northern Hemisphere biospheric exchange is underestimated by the climatologicalmean CASA net ecosystem exchange used in our simulations. From the SCA in $\left\langle\mathrm{CO}_{2}\right\rangle$ at the Park Falls, Wisconsin TCCON site, Yang et al. (2007) concluded that Northern Hemisphere growing season net flux is underestimated by $\sim 30 \%$ in the mean of TransCom inversions.

Here, we use additional TCCON data from other sites to show that this NEE underestimation is traceable to boreal regions. Simulations presented in KWS11, in which CASA NEE was increased in the subtropics and midlatitudes, could not simultaneously rectify the SCA and the north-south gradient in $\left\langle\mathrm{CO}_{2}\right\rangle$. In this paper, we show that the SCAs at four Northern Hemisphere TCCON sites are consistent with a boreal NEE integrated over $45-65^{\circ} \mathrm{N}$ that is increased by $40 \%$. Because column SCA is influenced by hemisphericscale fluxes, we can simultaneously improve the SCA fit at all four sites through boreal flux amplification. We also find that $\left\langle\mathrm{CO}_{2}\right\rangle$ simulated using CASA NEE with amplified boreal fluxes better matches the contrast in $\left\langle\mathrm{CO}_{2}\right\rangle$ across the Northern Hemisphere TCCON sites. The estimated gradient $\partial_{y} \widehat{\left\langle\mathrm{CO}_{2}\right\rangle}$ at Park Falls is misrepresented by $45 \%$ using CASA fluxes. Both $\widehat{\partial_{y}\left\langle\mathrm{CO}_{2}\right\rangle}$ at Park Falls and Lamont and from INTEX data are better represented using boreal amplified fluxes.

While CASA is only one biospheric flux model, and we have not examined its interannual flux variability in the simulations described in this paper, it is quite commonly used for biospheric and atmospheric science and is related to many other biospheric flux models. An underestimation of terrestrial exchange at high latitudes points to significant error 


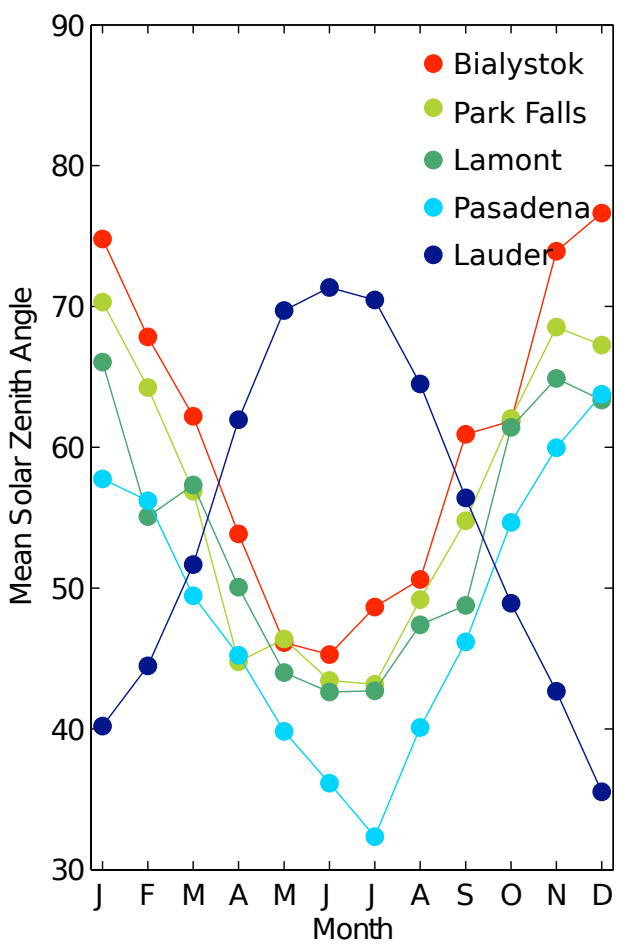

Fig. B1. Monthly mean solar zenith angles for TCCON sites.

in the description of boreal ecosystem fluxes and suggests further research is necessary to determine the representativeness of available flux data. In terms of future atmospheric $\mathrm{CO}_{2}$ levels, understanding boreal ecosystem functioning is important, as climate change is amplified in this region (Holland and Bitz, 2003).

Results from atmospheric inversion studies using surface data show that the net Northern Hemisphere terrestrial carbon sink is sensitive to the gross seasonal fluxes (Gurney et al., 2004). The correlation between seasonal land flux amplitude and net terrestrial uptake in TransCom inversion results underscores the utility of column data as a constraint on the mass gradient in atmospheric $\mathrm{CO}_{2}$. The large seasonality in Northern Hemisphere NEE necessary to account for variations in $\left\langle\mathrm{CO}_{2}\right\rangle$ data suggest that the Northern Hemisphere terrestrial biosphere may provide only a small net sink for anthropogenic $\mathrm{CO}_{2}$. In this paper, we demonstrate that the statistics of variations in $\left\langle\mathrm{CO}_{2}\right\rangle$ can provide important insights into the distribution of seasonal fluxes, but we anticipate results from a full inversion of column and boundary layer $\mathrm{CO}_{2}$ data will provide robust constraints on both seasonal and net fluxes.

\section{Appendix A}

\section{Removing local pollution}

The TCCON site in Pasadena is located within the Los Angeles basin, a megacity with extensive anthropogenic emissions of $\mathrm{CO}_{2}$ from traffic and other sources. Wunch et al. (2009) document that $\mathrm{CO}_{2}$ covaries diurnally with $\mathrm{CO}$, due to local pollution. We remove the local anthropogenic component of $\mathrm{CO}_{2}$ from the timeseries using its correlation with $\mathrm{CO}$. We take a twenty day running mean of the daily median $\langle\mathrm{CO}\rangle$, and shift it down by $20 \mathrm{ppb}$ so that it skims the bottom of the retrieved $\langle\mathrm{CO}\rangle$, representing the clean air $\langle\mathrm{CO}\rangle$. We use the following equation to correct $\left\langle\mathrm{CO}_{2}\right\rangle$ based on the offset of coretrieved $\langle\mathrm{CO}\rangle$ from its clean air value:

$\left\langle\mathrm{CO}_{2}\right\rangle_{\text {clean }}=\left\langle\mathrm{CO}_{2}\right\rangle-\frac{\langle\mathrm{CO}\rangle-(\overline{\langle\mathrm{CO}\rangle}-0.02 \mathrm{ppm})}{\mathrm{EF}}$

where $\mathrm{EF}$ represents the emission factor between $\mathrm{CO}$ and $\mathrm{CO}_{2}$ in the basin, equal to 0.011 , the slope obtained when $\left\langle\mathrm{CO}_{2}\right\rangle$ is regressed against $\langle\mathrm{CO}\rangle$. This value is consistent with combustion efficiency of auto engines of $\sim 99 \%$. The clean air $\left\langle\mathrm{CO}_{2}\right\rangle$ is generally less by $\sim 0.9 \mathrm{ppm}$ compared to the standard retrieval, and the intraseasonal standard deviation is slightly smaller $(\sim 1 \mathrm{ppm})$.

\section{Appendix B}

\section{Averaging kernels}

Retrieved $\left\langle\mathrm{CO}_{2}\right\rangle$ represents the best estimate of the atmospheric composition given a measured spectrum and a set of prior knowledge about the state of the atmophsere at the time of the observation. Comparing remotely sensed $\left\langle\mathrm{CO}_{2}\right\rangle$ with the model requires proper accounting of the non-ideality of the observing system via the averaging kernel. The averaging kernel, $\mathbf{A}$, represents the sensitivity of the retrieval at any level to the observed spectrum, and is ideally, though rarely, a unit matrix:

$\hat{\boldsymbol{x}}=\mathbf{A}\left(\boldsymbol{x}-\boldsymbol{x}_{a}\right)+\boldsymbol{x}_{a}+\epsilon$.

As expressed in Rodgers and Connor (2003), the retrieved quantity $\hat{\boldsymbol{x}}$ is sensitive to the prior profile $\boldsymbol{x}_{a}$, as well as to the true atmospheric composition $\boldsymbol{x}$. In an ideal case, $\mathbf{A}$ is the identity matrix and $\hat{\boldsymbol{x}}=\boldsymbol{x}$. For our $\mathrm{CO}_{2}$ retrievals, which use a profile scaling technique, the value of $\mathbf{A}$ at each pressure level is generally between 0.5 and 1.5 (see Fig. 3 of Wunch et al., 2010), depending on solar zenith angle and pressure.

When using remote sensing data in a comparison, the data obtained at higher vertical resolution should be smoothed by the averaging kernel of the data with lower vertical resolution (such as the column, which contains no vertical information). Therefore, in a comparison with eddy covariance observations, which contain information at the surface, we 
weight the eddy covariance observations by the surface averaging kernel. For comparison with the model output, where we integrate the $\mathrm{CO}_{2}$ mixing ratio at 25 levels to determine $\left\langle\mathrm{CO}_{2}\right\rangle$, we must apply the averaging kernel at each level.

We apply the FTS averaging kernels to AM2 data by calculating a monthly mean solar zenith angle (SZA) for spectra obtained at each site (Fig. B1). We likewise calculate the mean $\mathrm{CO}_{2}$ profile used in GFIT. GFIT uses prior profiles based on GLOBALVIEW-CO2 and incorporates the seasonal cycle and secular increase of $\mathrm{CO}_{2}$. These prior profiles are recentered to the model $\left\langle\mathrm{CO}_{2}\right\rangle$, maintaining the profile shape. The averaging kernel corresponding to the appropriate monthly mean SZA and the daily a priori profile are interpolated to the pressure profile over each site in AM2. The AM2 $\left\langle\mathrm{CO}_{2}\right\rangle$ incorporating the averaging kernels are then calculated as

$$
\left\langle\mathrm{CO}_{2}\right\rangle=\frac{\int\left\{\boldsymbol{A}\left(\left[\mathrm{CO}_{2}\right]-\left[\mathrm{CO}_{2}\right]_{p}\right)+\left[\mathrm{CO}_{2}\right]_{p}\right\} \mathrm{d} p}{\int\left(1-\mathbf{q}_{p}\right) \mathrm{d} p},
$$

where $\left[\mathrm{CO}_{2}\right]_{p}$ is the prior value and $q$ is the water vapor mixing ratio.

We use a simplified parameterization of the averaging kernel for our model (i.e., monthly mean profiles and averaging kernels) to reduce the computational intensity of the comparison and because we use daily mean $\mathrm{CO}_{2}$ model output, therefore we cannot take into account actual solar zenith angles. We find that applying the FTS averaging kernel to AM2 output has only a small effect on large-scale diagnostics in $\mathrm{AM} 2$, such as the seasonal cycle amplitude $(<0.2 \mathrm{ppm})$ or the estimated north-south gradient $\left(<0.01 \mathrm{ppb} \mathrm{km}^{-1}\right)$. Therefore, we are satisfied that for these bulk diagnostics, our method is sufficient.

Acknowledgements. Support for this work from NASA Carbon Cycle Program grant NNX08AI86G is gratefully acknowledged. GKA acknowledges fellowships from NSF and AAUW. The simulations used in this study were performed on the Caltech Division of Geological and Planetary Sciences Dell Cluster. Lauder TCCON measurements are funded by New Zealand Foundation of Research Science and Technology contracts C01X0204, C01X0703, and C01X0406. HIPPO is supported by the National Science Foundation and the National Ocean and Atmosphere Administration. CarbonTracker 2009 results were provided by NOAA ESRL, Boulder, Colorado, USA from the website at http://carbontracker.noaa.gov. LEF flux tower observations were made possible with assistance from A. Andrews (NOAA), J. Thom (UW), D. Baumann and M. Kubiske (USFS), and R. Strand and J. Ayers of the Wisconsin Educational Communications Board, and supported by Department of Energy (DOE) Office of Biological and Environmental Research (BER) National Institute for Climatic Change Research (NICCR) Midwestern Region Subagreement $050516 Z 19$ and the National Science Foundation (NSF) Biology Directorate Grant DEB-0845166. RJA was sponsored by US Department of Energy, Office of Science, Biological and Environmental Research (BER) programs and performed at Oak Ridge National Laboratory (ORNL) under US Department of Energy contract DE-AC05-00OR22725. We acknowledge financial support by the Senate of Bremen and the EU projects IMECC and GEOmon as well as maintainance and logistical work provided by AeroMeteo Service (Bialystok).

Edited by: M. Dai

\section{References}

Anderson, J. L., Balaji, V., Broccoli, A. J., Cooke, W. F., Delworth, T. L., Dixon, K. W., Donner, L. J., Dunne, K. A., Freidenreich, S. M., Garner, S. T., Gudgel, R. G., Gordon, C. T., Held, I. M., Hemler, R. S., Horowitz, L. W., Klein, S. A., Knutson, T. R., Kushner, P. J., Langenhost, A. R., Lau, N. C., Liang, Z., Malyshev, S. L., Milly, P. C. D., Nath, M. J., Ploshay, J. J., Ramaswamy, V., Schwarzkopf, M. D., Shevliakova, E., Sirutis, J. J., Soden, B. J., Stern, W. F., Thompson, L. A., Wilson, R. J., Wittenberg, A. T., and Wyman, B. L.: The new GFDL global atmosphere and land model AM2-LM2: Evaluation with prescribed SST simulations, J. Climate, 17, 4641-4673, 2004.

Andres, R. J., Marland, G., Fung, I., and Matthews, E.: A $1^{\circ} \times 1^{\circ}$ Distribution of Carbon Dioxide Emissions From Fossil Fuel Consumption and Cement Manufacture, Global Biogeochem. Cy., 10, 419-429, doi:10.1029/96GB01523, 1996.

Andres, R. J., Gregg, J. S., Losey, L., Marland, G., and Boden, T. A.: Monthly, global emissions of carbon dioxide from fossil fuel consumption, Tellus B, 63, 309-327, doi:10.1111/j.16000889.2011.00530.x, 2011.

Andrews, A. E., Boering, K. A., Daube, B. C., Wofsy, S. C., Loewenstein, M., Jost, H., Podolske, J. R., Webster, C. R., Herman, R. L., Scott, D. C., Flesch, G. J., Moyer, E. J., Elkins, J. W., Dutton, G. S., Hurst, D. F., Moore, F. L., Ray, E. A., Romashkin, P. A., and Strahan, S. E.: Mean ages of stratospheric air derived from in situ observations of $\mathrm{CO}_{2}, \mathrm{CH}_{4}$, and $\mathrm{N}_{2} \mathrm{O}$, J. Geophys. Res.-Atmos., 106, 32295-32314, 2001.

Baldocchi, D.: Breathing of the terrestrial biosphere: lessons learned from a global network of carbon dioxide flux measurement systems, Aust. J. Bot., 56, 1-26, 2008.

Bakwin, P. S., Tans, P. P., Hurst, D. F., and Zhao, C. L.: Measurements of carbon dioxide on very tall towers: results of the NOAA/CMDL program, Tellus B, 50, 401-415, 1998.

Beer, C., Reichstein, M., Tomelleri, E., Ciais, P., Jung, M., Carvalhais, N., Rodenbeck, C., Arain, M. A., Baldocchi, D., Bonan, G. B., Bondeau, A., Cescatti, A., Lasslop, G., Lindroth, A., Lomas, M., Luyssaert, S., Margolis, H., Oleson, K. W., Roupsard, O., Veenendaal, E., Viovy, N., Williams, C., Woodward, F. I., and Papale, D.: Terrestrial Gross Carbon Dioxide Uptake: Global Distribution and Covariation with Climate, Science, 329, 834-838, doi:10.1126/science.1184984, 2010.

Berger, B. W., Davis, K. J., Yi, C. X., Bakwin, P. S., and Zhao, C. L.: Long-term carbon dioxide fluxes from a very tall tower in a northern forest: Flux measurement methodology, J. Atmos. Ocean. Tech., 18, 529-542, 2001.

Choi, Y. H., Vay, S. A., Vadrevu, K. P., Soja, A. J., Woo, J. H., Nolf, S. R., Sachse, G. W., Diskin, G. S., Blake, D. R., Blake, N. J., Singh, H. B., Avery, M. A., Fried, A., Pfister, L., and Fuelberg, H. E.: Characteristics of the atmospheric CO2 signal as observed over the conterminous United States during INTEX-NA, J. Geophys. Res.-Atmos., 113, D07301, doi:10.1029/2007JD008899, 2008. 
Davis, K. J., Bakwin, P. S., Yi, C., Berger, B. W., Zhao, C., Teclaw, R. M., and Isebrands, J. G.: The annual cycles of $\mathrm{CO}_{2}$ and $\mathrm{H}_{2} \mathrm{O}$ exchange over a northern mixed forest as observed from a very tall tower, Glob. Change Biol., 9, 1278-1293, doi:10.1046/j.1365-2486.2003.00672.x, 2003.

Denning, A. S., Fung, I. Y., and Randall, D.: Latitudinal gradient of Atmospheric $\mathrm{CO}_{2}$ Due to seasonal exchange with land biota, Nature, 376, 240-243, 1995.

Desai, A. R., Helliker, B. R., Moorcroft, P. R., Andrews, A. E., and Berry, J. A.: Climatic controls in interannual variability in regional carbon fluxes from top-down and bottomup perspective, J. Geophys. Res.-Biogeosci., 115, G02011, doi:10.1029/2009JG001122, 2010.

Frankenberg, C., Butz, A., and Toon, G. C.: Disentangling chlorophyll fluorescence effects in $\mathrm{O}_{2}$ A-band spectra of reflected sunlight, J. Geophys. Res.-Atmos., 38, L03801, doi:10.1029/2010GL045896, 2011.

Gloor, M., Sarmiento, J. L., and Gruber, N.: What can be learned about carbon cycle climate feedbacks from the $\mathrm{CO}_{2}$ airborne fraction?, Atmos. Chem. Phys., 10, 7739-7751, doi:10.5194/acp-10-7739-2010, 2010.

Gregg, J. S. and Andres, R. J.: A method for estimating the temporal and spatial patterns of carbon dioxide emissions from national fossil-fuel consumption, Tellus B, 60, 1-10, 2008.

Gregg, J. S., Losey, L. M., Andres, R. J., Blasing, T. J., and Marland, G.: The Temporal and Spatial Distribution of Carbon Dioxide Emissions from Fossil-Fuel Use in North America, J. Appl. Meteorol. Clim., 48, 2528-2542, 2009.

Gurney, K. R., Law, R. M., Denning, A. S., Rayner, P. J., Baker, D., Bousquet, P., Bruhwiler, L., Chen, Y.-H., Ciais, P., Fan, S., Fung, I. Y., Gloor, M., Heimann, M., Higuchi, K., John, J., Maki, T., Maksyutov, S., Masarie, K., Peylin, P., Prather, M., Pak, B. C., Randerson, J., Sarmiento, J., Taguchi, S., Takahashi, T., and Yuen, C.-W.: Towards robust regional estimates of $\mathrm{CO}_{2}$ sources and sinks using atmospheric transport models, Nature, 415, 626-630, doi:10.1038/415626a, 2002.

Gurney, K. R., Law, R. M., Denning, A. S., Rayner, P. J., Pak, B. C., Baker, D., Bousquet, P., Bruhwiler, L., Chen, Y.-H., Ciais, P., Fung, I. Y., Heimann, M., John, J., Maki, T., Maksyutov, S., Peylin, P., Prather, M., and Taguchi, S.: Transcom 3 inversion intercomparison: Model mean results for the estimation of seasonal carbon sources and sinks, Global Biogeochem. Cy., 18, GB1010, doi:10.1029/2003GB002111, 2004.

Holland, M. M. and Bitz, C. M.: Polar amplification of climate change in coupled models, Clim. Dynam., 21, 221-232, 2003.

Horst, T. W. and Weil, J. C.: Footprint estimation for scalar flux measurements in the atmospheric surface layer, Bound. Lay. Meteorol., 59, 279-276, 1992.

Kalnay, E., Kanamitsu, M., Kistler, R., Collins, W., Deaven, D., Gandin, L., Iredell, M., Saha, S., White, G., Woollen, J., Zhu, Y., Chelliah, M., Ebisuzaki, W., Higgins, W., Janowiak, J., Mo, K. C., Ropelewski, C., Wang, J., Leetmaa, A., Reynolds, R., Jenne, R., and Joseph, D.: The NCEP/NCAR 40-year reanalysis project, B. Am. Meteorol. Soc., 77, 437-471, 1996.

Keeling, R. F., Piper, S. C., and Heimann, M.: Global and hemispheric $\mathrm{CO}_{2}$ sinks deduced from changes in atmospheric $\mathrm{O}_{2}$ concentration, Nature, 381, 218-221, 1996.

Keppel-Aleks, G., Wennberg, P. O., and Schneider, T.: Sources of variations in total column carbon dioxide, Atmos. Chem. Phys.,
11, 3581-3593, doi:10.5194/acp-11-3581-2011, 2011.

Manning, A. C. and Keeling, R. F.: Global oceanic and land biotic carbon sinks from the Scripps atmospheric oxygen flask sampling network, Tellus B, 58, 95-116, 2006.

Marland, G. and Rotty, R. M.: Carbon-dioxide Emissions From Fossil-fuels - A Procedure For Estimation and Results For 1950 1982, Tellus B, 36, 232-261, 1984.

Mesinger, F., DiMego, G., Kalnay, E., Mitchell, K., Shafran, P. C., Ebisuzaki, W., Jovic, D., Woollen, J., Rogers, E., Berbery, E. H., Ek, M. B., Fan, Y., Grumbine, R., Higgins, W., Li, H., Lin, Y., Manikin, G., Parrish, D., and Shi, W.: North American regional reanalysis, B. Am. Meteorol. Soc., 87, 343-360, doi:10.1175/BAMS-87-3-343, 2006.

Nakatsuka, Y. and Maksyutov, S.: Optimization of the seasonal cycles of simulated $\mathrm{CO}_{2}$ flux by fitting simulated atmospheric $\mathrm{CO}_{2}$ to observed vertical profiles, Biogeosciences, 6, 27332741, doi:10.5194/bg-6-2733-2009, 2009.

Olsen, S. C. and Randerson, J. T.: Differences between surface and column atmospheric $\mathrm{CO}_{2}$ and implications for carbon cycle research, J. Geophys. Res., 109, D02301, doi:10.1029/2003JD003968, 2004.

Peters, W., Jacobson, A. R., Sweeney, C., Andrews, A. E., Conway, T. J., Masarie, K., Miller, J. B., Bruhwiler, L. M. P., Pétron, G., Hirsch, A. I., Worthy, D. E. J., van der Werf, G. R., Randerson, J. T., Wennberg, P. O., Krol, M. C., and Tans, P. P.: An atmospheric perspective on North American carbon dioxide exchange: CarbonTracker, P. Natl. Acad. Sci., 104, 18925-18930, doi:10.1073/pnas.0708986104, 2007.

Randerson, J. T., Thompson, M. V., Conway, T. J., Fung, I. Y., and Field, C. B.: The contribution of terrestrial sources and sinks to trends in the seasonal cycle of atmospheric carbon dioxide, Global Biogeochem. Cy., 11, 535-560, 1997.

Rayner, P. J. and O'Brien, D. M.: The utility of remotely sensed $\mathrm{CO}_{2}$ concentration data in surface source inversions, Geophys. Res. Lett., 28, 175-178, 2001.

Ricciuto, D. M., Davis, K. J., and Keller, K.: A Bayesian calibration of a simple carbon cycle model: The role of observations in estimating and reducing uncertainty, Glob. Biogeochem. Cy., 22, GB2030, doi:10.1029/2006GB002908, 2008.

Rodgers, C. D. and Connor, B. J.: Intercomparison of remote sounding instruments, J. Geophys. Res., 108, 4116, doi:10.1029/2002JD002299, 2003.

Saatchi, S. S., Houghton, R. A., Alvala, R. C. D. S., Soares, J. V., and Yu, Y.: Distribution of aboveground live biomass in the Amazon basin, Glob. Change Biol., 13, 816-837, doi:10.1111/j.1365-2486.2007.01323.x, 2007.

Stephens, B. B., Gurney, K. R., Tans, P. P., Sweeney, C., Peters, W., Bruhwiler, L., Ciais, P., Ramonet, M., Bousquet, P., Nakazawa, T., Aoki, S., Machida, T., Inoue, G., Vinnichenko, N., Lloyd, J., Jordan, A., Heimann, M., Shibistova, O., Langenfelds, R. L., Steele, L. P., Francey, R. J., and Denning, A. S.: Weak northern and strong tropical land carbon uptake from vertical profiles of atmospheric $\mathrm{CO}_{2}$, Science, 316, 1732-1735, doi:10.1126/science.1137004, 2007.

Takahashi, T., Sutherland, S. C., Sweeney, C., Poisson, A., Metzl, N., Tilbrook, B., Bates, N., Wanninkhof, R., Feely, R. A., Sabine, C., Olafsson, J., and Nojiri, Y.: Global sea-air $\mathrm{CO}_{2}$ flux based on climatological surface ocean $p \mathrm{CO}_{2}$, and seasonal biological and temperature effects, Deep-Sea Res. Pt II, 49, 1601-1622, 2002. 
Tohjima, Y., Machida, T., Watai, T., Akama, I., Amari, T., and Moriwaki, Y.: Preparation of gravimetric standards for measurements of atmospheric oxygen and reevaluation of atmospheric oxygen concentration, J. Geophys. Res., 10, D11302, doi:10.1029/2004JD005595, 2005.

van der Werf, G. R., Randerson, J. T., Giglio, L., Collatz, G. J., Kasibhatla, P. S., and Arellano Jr., A. F.: Interannual variability in global biomass burning emissions from 1997 to 2004, Atmos. Chem. Phys., 6, 3423-3441, doi:10.5194/acp-6-3423-2006, 2006.

Vay, S. A., Woo, J. H., Anderson, B. E., Thornhill, K. L., Blake, D. R., Westberg, D. J., Kiley, C. M., Avery, M. A., Sachse, G. W., Streets, D. G., Tsutsumi, Y., and Nolf, S. R.: Influence of regional-scale anthropogenic emissions on $\mathrm{CO}_{2}$ distributions over the western North Pacific, J. Geophys. Res.-Atmos., 108, 8801, doi:10.1029/2002JD003094, 2003.

Wang, W. G., Davis, K. J., Cook, B. D., Bakwin, P. S., Yi, C. X., Butler, M. P., and Ricciuto, D. A.: Surface layer $\mathrm{CO}_{2}$ budget and advective contributions to measurements of net ecosystematmosphere exchange of $\mathrm{CO}_{2}$, Agr. Forest Meteorol., 135, 202214,2005

Wang, W. G, Davis, K. J., Cook, B. D., Butler, M. P., and Ricciuto, D. M.: Decomposing $\mathrm{CO}_{2}$ fluxes measured over a mixed ecosystem at a tall tower and extending to a region: A case study, J. Geophys. Res., 111, G02005, doi:10.1016/j.agrformet.2005.11.018, 2006.

Washenfelder, R. A., Toon, G. C., Blavier, J.-F., Yang, Z., Allen, N. T., Wennberg, P. O., Vay, S. A., Matross, D. M., and Daube, B. C.: Carbon dioxide column abundances at the Wisconsin Tall Tower site, J. Geophys. Res., 111, D22305, doi:10.1029/2006JD007154, 2006.

Wofsy, S. C. and the HIPPO Science Team: HIAPER Pole-to-Pole Observations (HIPPO): Fine grained, global scale measurements of climatically important atmospheric gases and aerosols, Philos. T. Roy. Soc. A, 369, 2073-2086, 2011.
Wunch, D., Wennberg, P. O., Toon, G. C., Keppel-Aleks, G., and Yavin, Y. G.: Emissions of greenhouse gases from a North American megacity, Geophys. Res. Lett., 36, L15810, doi:10.1029/2009GL039825, 2009.

Wunch, D., Toon, G. C., Wennberg, P. O., Wofsy, S. C., Stephens, B. B., Fischer, M. L., Uchino, O., Abshire, J. B., Bernath, P., Biraud, S. C., Blavier, J.-F. L., Boone, C., Bowman, K. P., Browell, E. V., Campos, T., Connor, B. J., Daube, B. C., Deutscher, N. M., Diao, M., Elkins, J. W., Gerbig, C., Gottlieb, E., Griffith, D. W. T., Hurst, D. F., Jiménez, R., Keppel-Aleks, G., Kort, E. A., Macatangay, R., Machida, T., Matsueda, H., Moore, F., Morino, I., Park, S., Robinson, J., Roehl, C. M., Sawa, Y., Sherlock, V., Sweeney, C., Tanaka, T., and Zondlo, M. A.: Calibration of the Total Carbon Column Observing Network using aircraft profile data, Atmos. Meas. Tech., 3, 1351-1362, doi:10.5194/amt-31351-2010, 2010.

Wunch, D., Toon, G., Blavier, J.-F. L., Washenfelder, R., Notholt, J., Connor, B., Griffith, D., Sherlock, V., and Wennberg, P.: The Total Carbon Column Observing Network, Philos. T. Roy. Soc. A, 369, 2087-2112, 2011.

Yang, Z., Washenfelder, R. A., Keppel-Aleks, G., Krakauer, N. Y., Randerson, J. T., Tans, P. P., Sweeney, C., and Wennberg, P. O.: New constraints on Northern Hemisphere growing season net flux, Geophys. Res. Lett., 34, L12807, doi:10.1029/2007GL029742, 2007.

Yi, C., Davis, K. J., Bakwin, P. S., Berger, B. W., and Marr, L. C.: Influence of advection on measurements of the net ecosystematmosphere exchange of $\mathrm{CO}_{2}$ from a very tall tower, J. Geophys. Res.-Atmos., 105, 9991-9999, 2000.

York, D., Evensen, N. M., Martinez, M. L., and Delgado, J. D.: Unified equations for the slope, intercept, and standard errors of the best straight line, Am. J. Phys., 72, 367-375, 2004.

Zhao, C. L., Bakwin, P. S., and Tans, P. P.: A design for unattended monitoring of carbon dioxide on a very tall tower, J. Atmos. Ocean. Tech., 14, 1139-1145, 1997. 